\title{
Perceived size and motion in depth from optical expansion
}

\author{
MICHAEL T. SWANSTON \\ Dundee College of Technology, Dundee, Scotland \\ and \\ WALTER C. GOGEL \\ University of California, Santa Barbara, California
}

\begin{abstract}
The research investigated the perceived motion in depth resulting from the optical expansion or contraction of objects. A theoretical analysis of this cue was made in terms of the size-distance invariance hypothesis. For presenting stimuli, a computer simulation was developed which simulated the physical motion in depth of a constant-sized object at a constant velocity. A series of experiments showed that the extent of perceived motion in depth did not relate to the change in perceived stimulus size as predicted by the size-distance invariance hypothesis. Instead, substantial perceptions of depth motion occurred even though the ratio of the terminal perceived sizes was similar to the ratio of the terminal visual angles. Extending past research, a theoretical account based on the existence of two distinct processes involved in responding to size and distance was applied successfully. One process expressed by the size-distance invariance hypothesis determines the response to immediate, sensorily specified information. The second process involves the effect of size remembered from a previous perception (off-sized judgments) upon the response to distance. As determined by measurement obtained from using the head motion procedure, this remembered (representational) size, as it occurs in successive instants of the optical expansion pattern, can be translated by the visual system into a robust perception of distance.
\end{abstract}

The perceived egocentric distance of an object contributes to many of its perceived characteristics. This is true, for example, of shape, movement, depth from retinal disparity, brightness, and size (Gogel, 1984). In the case of perceived size, it is well known that if a stimulus of constant visual angle is perceived to be at different distances, its size will appear to vary directly with its perceived distance. This can readily be seen when an afterimage is projected onto surfaces at different perceived distances and thereby appears larger or smaller as its perceived distance increases or decreases, respectively (Emmert, 1881). This is an instance of size-distance invariance, in which the modification of perceived distance by the tendency for the stimulus to be seen as equidistant with the adjacent parts of the background also modifies the perceived size of the stimulus. A general form of the sizedistance invariance hypothesis (SDIH) is that the ratio of

This research, completed at the University of California, Santa Barbara, was supported jointly by the United States Public Health Service Grant MH 39457 from the National Institute of Mental Health to Walter C. Gogel and by the International Research Fellowship Program, Fogarty International Center, National Institutes of Health, Fellowship 1 F05TW03515-01 to Michael T. Swanston, with Walter C. Gogel, Sponsor. Both authors are equally responsible for the research and preparation of the paper. Reprint requests can be addressed to either author. M. T. Swanston's mailing address is Dundee College of Technology, Bell Street, Dundee DD11HG, Scotland. W. C. Gogel's address is Psychology Department, University of California, Santa Barbara, CA 93106. perceived size $\left(S^{\prime}\right)$ to perceived distance $\left(D^{\prime}\right)$ is proportional to the ratio of physical size $(S)$ to physical distance (D). Thus:

$$
S^{\prime} / D^{\prime}=S / D=\tan \theta,
$$

where $\theta$ is the angle subtended by the stimulus at the nodal point of the eye (Gilinsky, 1951; Kilpatrick \& Ittelson, 1953; Schlosberg, 1950). If $S$ is small as compared with $D$, then $S / D$ approximates the visual angle of the stimulus expressed in radians.

The purpose of the experiments described here was to investigate the application of the SDIH to the motion in depth and the change in size that is perceived when objects undergo a continuous change in visual angle. This situation, which is often known as an optical expansion pattern, has been shown to be an effective stimulus for perceived motion in depth (Ittelson, 1951; Johansson, 1964; Marmolin, 1973a, 1973b; Regan \& Beverley, 1978; Wheatstone, 1852). Although there has been considerable interest in the theoretical properties of optical expansion as a potential source of information for biological or computational visual systems (e.g., Lee, 1980; Nakayama \& Loomis, 1974), the interrelationship between perceived size and perceived distance in optical expansion as expressed by the SDIH has seldom been explicitly examined. Noguchi and Taya (1981) measured both perceived size and perceived distance for an object moving physically toward and away from an observer, and found that size- 
distance invariance held approximately. However, in addition to optical expansion, residual cues to distance, such as accommodation and accommodative convergence, also varied with physical distance, and it is hard to know what part these may have played in the results.

Examples of several possible perceptions associated with optical expansion and consistent with the SDIH are shown in Figure 1 for the case in which the expansion stimulus always is at a constant physical distance from the observer. In the figures, the primed notation refers to perceived characteristics and the unprimed notation to physical characteristics. Also, the subscripts $n$ and $f$ refer to the nearest and farthest distance simulated by the stimulus change. Thus, for example $S_{f}^{\prime}, D_{f}^{\prime}$, and $\theta_{f}$, etc., refer to the perceived size, perceived distance, and visual angle, etc., of the farthest simulated distance. Definitions of the terms used in the figures and throughout the text are listed in the appendix. The stimulus represented in Figure 1 is a line or rectangle that expands physically from a size $S_{f}$ to a size $S_{n}$, or contracts physically from a size $S_{n}$ to a size $S_{f}$, in continuous repeated cycles. Figure 1A
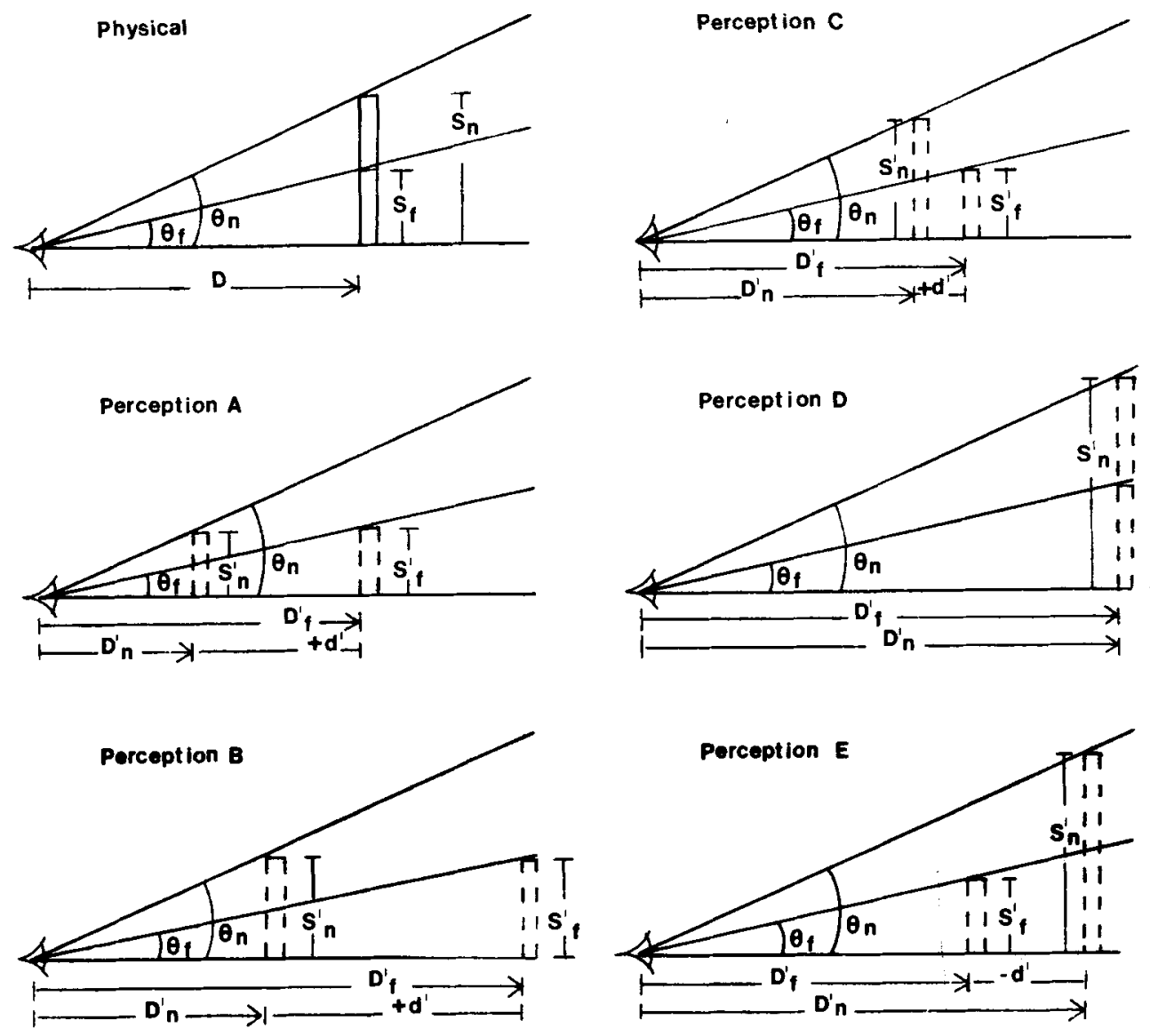

Figure 1. Schematic diagrams illustrating perceptions of size and distance from optical expansion consistent with the size-distance invariance hypothesis. The physical stimulus is shown in the upper left drawing with $S$, $D$, and $\theta$, the physical size, distance, and visual angle at the far $(f)$ and near $(n)$ simulated distances. The different possible perceptions at the near and far simulated distances are indicated by $S^{\prime}$ and $D^{\prime}$ in the remaining drawings. Drawings A through $\mathbf{E}$ illustrate the inverse relationship between the change in perceived depth $\left(d^{\prime}\right)$ and the change in perceived size $\left(S_{n}^{\prime}-S_{f}\right)$. See text for additional discussion. 
fective perceptually in this case also, the perceived size of the stimulus again would be constant $\left(S_{n}^{\prime}=S_{f}\right)$, but larger than in Figure 1A, and the object would appear to move through a depth $d^{\prime}$, which is greater than that in Figure 1A. In Figure 1C, the perceived size of the object increases as the stimulus expands $\left(S_{n}^{\prime}>S_{f}\right)$ and, corresponding to this reduction in constancy of perceived size, the apparent motion of the stimulus in depth $\left(d^{\prime}\right)$ is reduced. In Figure 1D, the optical expansion is totally ineffective as a cue of motion in depth, the stimulus always appears at the same distance from the observer $\left(D_{n}^{\prime}=D_{f}^{\prime}\right)$, and the ratio of the perceived terminal sizes $\left(S_{n}^{\prime} / S_{f}^{\prime}\right)$ is the same as the ratio of the terminal visual angles $\left(\theta_{n} / \theta_{f}\right)$ used in the expansion. In Figure 1E, a situation is shown in which the ratio of the terminal perceived sizes is greater than the visual angles $\left(S_{n}^{\prime} / S_{f}^{\prime}>\theta_{n} / \theta_{f}\right)$. In this case, in order to be consistent with the SDIH, the perception of motion in depth $\left(d^{\prime}\right)$ would be opposite in direction to that illustrated in Figures $1 \mathrm{~A}, 1 \mathrm{~B}$, or $1 \mathrm{C}$. There are, indeed, very many perceptual outcomes from optical expansion that are consistent with the SDIH. However, as suggested by Figure 1, this consistency requires an inverse relationship between the change in perceived size and the change in perceived distance. This relationship can be specified from Equation 1 as:

$$
S_{f}^{\prime} / \tan \theta_{f}-S_{n}^{\prime} / \tan \theta_{n}=D_{f}^{\prime}-D_{n}^{\prime}=d^{\prime} .
$$

Given the terminal visual angles $\theta_{f}$ and $\theta_{n}$ and the obtained experimental values of $S_{f}^{\prime}$ and $S_{n}^{\prime}$ at these angles, the $d^{\prime}$ predicted from Equation 2 can be compared with the experimentally obtained $d^{\prime}$. This comparison evaluates the applicability of the SDIH to perceptions resulting from optical expansion.

If $S_{n}^{\prime} / S_{f}^{\prime}$ is equal to or greater than $\theta_{n} / \theta_{f}$, it follows from the above discussion of the SDIH that the perceived motion in depth from optical expansion should be zero (Figure 1D) or should be to a greater perceived distance for the larger visual angle (Figure 1E). But, as will be seen, the results obtained in the present study indicate that a perceived sagittal motion $\left(d^{\prime}\right)$ in the directions shown in Drawings A, B, and C occurred as the angle expanded or contracted even though the ratio of the near to far perceived sizes equaled or exceeded the ratio of corresponding retinal sizes. This consistently obtained result does not agree with Equation 2, indicating that the SDIH, as expressed by Equations 1 and 2, is not always adequate to explain the changes in perceived size and perceived distance associated with an optical expansion.

It should be noted also that, except perhaps hypothetically in the case of the optical expansion of a familiar object, an expansion pattern does not provide information as to the perceived distance $\left(D^{\prime}\right)$ of the stimulus from the observer. In the present study, it was found that the initial far simulated distance usually was perceived to be larger than the physical distance of the display monitor as computed from the perceived size using the SDIH. This increase in $D_{f}^{\prime}$ beyond the value expected from oculomotor cues associated with the physical distance to the display is attributed to the influence of the specific distance tendency. This is a tendency, in the absence of effective cues of distance, to perceive an object at about 2 or $3 \mathrm{~m}$ from the observer (Gogel, 1969; Gogel \& Tietz, 1973), or, in the presence of some partial (residual) cues, to modify the perceived distance of the object in the direction of this 2- to 3-m distance.

The failure of the relations indicated by Equation 2 to correspond to the perceptual data from optical expansion requires that a different paradigm be sought to explain the perceptions associated with optical expansion. An explanation based on what has been termed "off-sized" perceptions or judgments can be applied. This model has been developed in a series of studies (Gogel, 1971, 1974, 1976, 1981; Gogel \& Sturm, 1971). There is evidence that observers expect that an object at a far distance will look smaller than the same object at a near distance (Carlson, 1960; Carlson \& Tassone, 1962). Probably, this is based upon the tendency to underestimate perceptually the distance of far objects as a consequence of the decrease in the number and effectiveness of cues to distance associated with objects at increasing physical distances. According to the SDIH, such perceptual underestimations of distance will result in a reduction in the perceived size of far objects relative to near objects of the same physical size. If the far object has a known, familiar, or assumed size, the result will be that the object will be judged to be smaller than normal (a small off-sized perception). Conversely, if the object is perceived to be more distant than its physical distance, it will be judged to be larger than normal (a large off-sized perception). Such judgments involve two components. One of these is $S^{\prime}$, the size of the test object as perceived. The other is $S_{c}$, the remembered, assumed, familiar, suggested, or standard size of the object against which the perceived size of the test object is evaluated. Unlike $S^{\prime}, S_{c}$ is the result of information not available in the immediate presentation of the test object. For example, in the case of familiar size, $S_{c}$ is the familiar, or assumed size as determined by experience with the size of objects presenting the same or a similar stimulus configuration. Thus, $S^{\prime}$ is a perception, whereas $S_{c}$, because it involves a memory or representation, has been called a cognition. Together, these two components define the "off-sized response" as $S_{c} / S^{\prime}$. Since one component $\left(S_{c}\right)$ is cognitive and the other $\left(S^{\prime}\right)$ is perceptual, $S_{c} / S^{\prime}$ might be called an "off-sized judgment" or an "off-sized perception," and both terms have been used (see Gogel, 1981, Footnote 1). If $S_{c}>S^{\prime}$, the test object is judged to be a small off-sized object. If $S_{c}<S^{\prime}$, the test object is judged to be a large off-sized object. If $S_{c}=S^{\prime}$, the test object is judged to be normal in size. Finally, in an effort to provide an accurate judgment of distance, the smaller or larger appearing off-sized object often will be judged to be at a distance that is greater or less, respec- 
tively, than the distance at which it is perceived (Gogel, $1969,1974)$. This has been called a cognitive response to distance and is labeled $D_{c}$. In equation form,

$$
D_{c}=D^{\prime}\left(S_{c} / S^{\prime}\right) \text {, }
$$

where $S_{c}$ is the cognitive size, $S^{\prime}$ is the perceived size, and $D^{\prime}$ is the perceived distance of the object. The usefulness of $D_{c}$ in usual conditions of observation is that it can correct for errors in perceived distance. For example, a distant person known to be $6 \mathrm{ft}$ tall $\left(S_{c}\right)$ may appear $\left(D^{\prime}\right)$ at half this physical distance and, therefore, will appear to be only half-sized $\left(S_{c} / S^{\prime}=2\right)$. If the observer's response to distance was determined by $D_{c}$, then, according to Equation 3, the distance response would be physically accurate, that is, since $D^{\prime}=1 / 2 D$ but $S_{c} / S^{\prime}=2$, $D_{c}=D$. In Equation 3, $S^{\prime}$ and $D^{\prime}$ are components of a perceptual (primary) process consistent with the SDIH. $D_{c}$ and $S_{c}$ have been considered to reflect a cognitive (secondary) process (see Gogel, 1974, 1976), not necessarily consistent with the SDIH, that can be available in addition to the primary process. However, one of the main conclusions from the present study is that the distance response to optical expansion (or contraction) can be perceptual even though the relation between the size and distance responses are inconsistent with the SDIH. This will be interpreted to mean that the remembered size, $S_{c}$, which is representational and thus possibly classified as cognitive, under some conditions of optical expansion can produce or modify a perception of depth.

It will be recalled that the results from optical expansion in the present study were that $S_{n}^{\prime} / S_{f}^{\prime}$ often was similar to $\theta_{n} / \theta_{f}$. It follows, according to the SDIH, that in the primary process, the apparent distance of the stimuli was approximately constant $\left(D_{n}^{\prime}=D_{f}^{\prime}\right)$, as in Figure $1 \mathrm{D}$. It is suggested that, in the optical expansion, the perceived size of the preceding stimulus became the standard $S_{\mathrm{c}}$ for the stimuli that followed. It is as though the observer assumes that it is the same object that is perceived as getting larger or smaller as it expands or contracts, respectively. The judged motion in depth of the object from the secondary process is the difference between $D_{c}$ (from Equation 3 ) at the near and far simulated distances. Consider $D_{c}$ at the start of an optical expansion. At that moment, the smallest visual angle $\left(\theta_{f}\right)$ is on the monitor and $D_{c}$ is at its largest value, that is, $D_{c}($ far $)=D_{f}^{\prime}\left(S_{c} / S^{\prime}\right)$. But $S_{c}=S_{f}^{\prime}$ and $S^{\prime}$ also equals $S_{f}^{\prime}$. Thus, $D_{c}(\mathrm{far})=D_{f}^{\prime}\left(S_{f}^{\prime} / S_{f}\right)=D_{f}^{\prime}$. Now, consider $D_{c}$ after the optical expansion has been completed. At that moment, the largest visual angle $\left(\theta_{n}\right)$ is on the monitor and $D_{c}$ is at its smallest value, that is, $D_{c}$ (near) $=D_{n}^{\prime}\left(S_{c} / S^{\prime}\right)$. But $S_{c}$ continues to equal $S_{f}^{\prime}, S^{\prime}$ now equals $S_{n}^{\prime}$, and, in the present study, $D_{n}^{\prime}=D_{f}^{\prime}$. Thus, $D_{c}$ (near) $=D_{f}^{\prime}\left(S_{f}^{\prime} / S_{n}^{\prime}\right)$. However, according to the primary process, if $\theta$ is expressed in radians, $S_{f}^{\prime}=\theta_{f} D_{f}^{\prime}$ and $S_{n}^{\prime}=$ $\theta_{n} D_{n}^{\prime}$. Thus, $D_{c}$ (near) $=D_{f}^{\prime}\left(\theta_{f} / \theta_{n}\right)$. But $d_{c}=D_{c}($ far $)-$ $D_{c}$ (near), and therefore,

$$
d_{c}=D_{f}^{\prime}-D_{f}^{\prime}\left(\theta_{f} / \theta_{n}\right)=D_{f}^{\prime}\left(\theta_{n}-\theta_{f}\right) / \theta_{n} .
$$

Also consider $D_{c}$ at the start of an optical contraction. At that moment, the largest visual angle $\left(\theta_{n}\right)$ is on the monitor and $D_{c}$ is at its smallest value, that is, $D_{c}$ (near) $=D_{n}^{\prime}\left(S_{c} / S^{\prime}\right)$. But $S_{c}=S_{n}^{\prime}, S^{\prime}$ also equals $S_{n}^{\prime}$, and, in this study, $D_{n}^{\prime}=D_{f}^{\prime}$. Thus, $D_{c}$ (near) $=D_{n}^{\prime}\left(S_{n}^{\prime} / S_{n}^{\prime}\right)=D_{f}^{\prime}$. Now, consider $D_{c}$ after the optical contraction has been completed. At this moment, the smallest visual angle $\theta_{f}$ is on the monitor and $D_{c}$ is at its largest value, that is, $D_{c}$ (far) $=D_{f}\left(S_{c} / S^{\prime}\right)$. But $S_{c}$ continues to equal $S_{n}^{\prime}$, and now $S^{\prime}$ equals $S_{f}^{\prime}$. Thus, $D_{c}($ far $)=D_{f}^{\prime}\left(S_{n}^{\prime} / S_{f}^{\prime}\right)$. But, again, according to the primary process $S_{f}^{\prime}=\theta_{f} D_{f}^{\prime}$ and $S_{n}^{\prime}=\theta_{n} D_{n}^{\prime}$ with $D_{n}^{\prime}$ in the present study essentially equal to $D_{f}^{\prime}$. Thus, $D_{c}$ (far) $=D_{f}^{\prime}\left(\theta_{n} / \theta_{f}\right)$. Again, $d_{c}=D_{c}($ far $)-D_{c}$ (near) and

$$
d_{c}=D_{f}^{\prime}\left(\theta_{n} / \theta_{f}\right)-D_{f}^{\prime}=D_{f}^{\prime}\left(\theta_{n}-\theta_{f}\right) / \theta_{f} .
$$

According to Equations 4 and 5 , when $D_{f}^{\prime}=D_{n}^{\prime}$, for the same change in $\theta, d_{c}$ will be larger for an optical contraction than for an optical expansion. However, if the expansion and contraction are continuously alternated, it is likely that the initial perception of size, whether from an expansion or a contraction, will determine $S_{c}$ for the entire duration of the optical changes. This does not mean that a long-term memory of the original $S_{c}$ is required, but only that the stimulus object is viewed as the same object despite its continuous change in apparent size. The term $S_{c}$ requires only the memory necessary to achieve object identity throughout the continuous successive expansions and contractions despite the changing $S^{\prime}$, thus providing for the continuous sequence of changing $S_{c} / S^{\prime}$ necessary for $d_{c}$. The difference between Equations 4 and 5 suggests that the $S_{c}$ to be applied to the stimulus change can be modified by whether the largest or smallest visual angle is used at the start of the change in $\theta$. Unlike Equation 3, however, Equations 4 and 5 apply only to conditions, as in the present study, in which $D^{\prime}$ of the primary process is constant. Also, it should be noted, in Equation 3, that $D_{c}=D^{\prime}$ whenever $S_{c}=S^{\prime}$. This means that if the stimulus is perceived to remain constant in size $\left(S_{c} / S^{\prime}=1\right)$ during the optical expansion or contraction, the primary and secondary processes are in agreement. Under conditions in which size of object is perceived as constant, the primary and secondary processes are complementary in producing a perception of sagittal motion.

Two studies (Gogel, 1976, 1981) support the conclusion that the secondary process based on off-sized judgments often can be regarded as being partially or totally cognitive rather than perceptual. In these studies, apparent distance was measured directly by verbal reports and indirectly by the head-motion procedure. The method of measuring apparent distance by the head-motion procedure is illustrated in Figure 2. In this figure, a stationary object, physically at a middle distance $D_{m}$, is viewed with lateral motion $(K)$ of the head. If the object appears closer $\left(D_{n}^{\prime}\right)$ than its physical distance, it will appear to move $\left(W^{\prime}\right)$ in the same direction as the head. If it appears more distant $\left(D_{f}^{\prime}\right)$ than its physical distance, it will appear to move $\left(-W^{\prime}\right)$ in a direction opposite to the head motion. If it appears at its physical distance, it will not appear to move as the head is moved laterally. The apparent distance of the object can be measured either by nulling out the apparent motion by an opposite physical motion of the ob- 


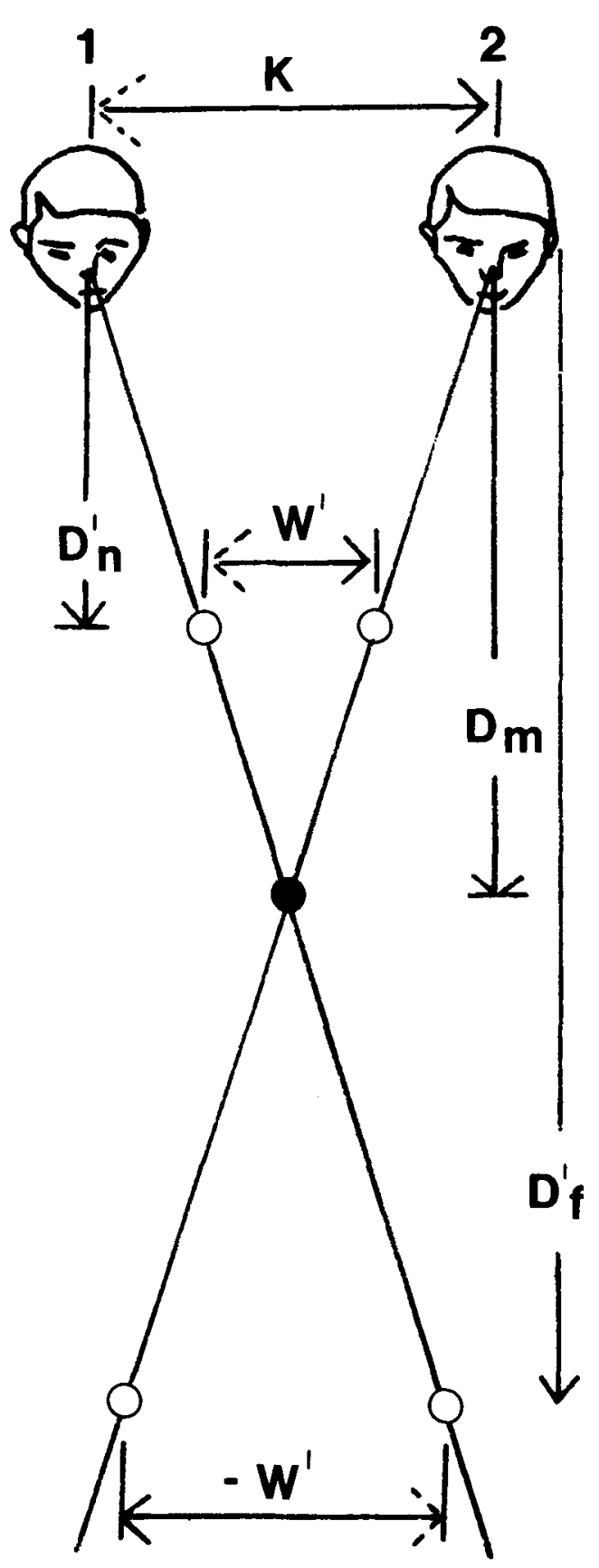

Figure 2. A drawing illustrating the procedure used in the present study to measure the perceived distance, $D^{\prime}$, of a stimulus viewed as the head is repetitively moved through a lateral extent, $K$. If the physically stationary stimulus is perceived at a distance less $\left(D_{n}^{\prime}\right)$ or more $\left(D_{f}\right)$ than its physical distance $\left(D_{m}\right)$, it will appear to move in the same direction as $\left(+W^{\prime}\right)$ or opposite to $\left(-W^{\prime}\right)$ the direction of the head motion, respectively. If it is perceived at its physical distance, it will not appear to move. Using Equation 6 and the observer's response as to the direction and amount of perceived motion of the stimulus, the perceived distance of the object can be calculated. ject or by measuring the apparent motion of the object concomitant with the motion of the head (Gogel, 1981, 1982). When the object is physically stationary, as in the present study, at a physical distance $D$ from the observer, its apparent distance can be measured, using the headmotion procedure, by the following equation:

$$
D^{\prime}=D\left(K-W^{\prime}\right) / K \text {. }
$$

Thus, given a constant $D$ and $K$ and an apparent motion concomitant with the motion of the head at near $D_{n}^{\prime}$ and far $D_{f}^{\prime}$ distances, the perceived motion in depth $\left(d^{\prime}\right)$, predicted from Equation 6 is

$$
d^{\prime}=D_{f}^{\prime}-D_{n}^{\prime}=D\left(W_{n}^{\prime}-W_{f}^{\prime}\right) / K .
$$

$W^{\prime}$ is positive or negative depending upon whether the apparent concomitant motion is in the same direction as, or opposite to, the direction of the head motion, respectively.

The head-motion procedure, unlike verbal reports of distance, is an indirect measure of perceived distance, since it uses the response to apparent lateral motion rather than to apparent distance per se. Thus, it is immune to cognitive modifications of reported distance from off-sized perceptions and can be applied in the present study as a criterion for determining whether direct reports of distance resulting from off-sized perceptions are indeed perceptual rather than cognitive. It has been applied for this purpose in several studies. In one study (Gogel, 1976), it was found that information regarding perceived size, conveyed by viewing familiar objects, had a pronounced effect upon verbal reports of distance and a much smaller (but significant) effect on perceived distance, as measured by the head-motion procedure. It was concluded that familiar size, by modifying perceived size, had some effect on perceived distance consistent with the SDIH, but that its much larger effect on verbal reports was mostly cognitive. In another study (Gogel, 1981), familiar objects were used to suggest sizes in geometrical (nonfamiliar) stimuli that had the same shape as the familiar objects. Although verbal reports of the distance of the stimuli clearly were strongly influenced by the suggestions, perceived distance, as measured by the head-motion procedure, was completely unaffected, that is, the modification of the verbal reports was cognitive, not perceptual. A third study, which provides additional evidence that the head-motion procedure is useful for distinguishing between cognitive and perceptual modifications in the response to distance is that of MacCracken, Gogel, and Blum (1980). In that study, posthypnotic suggestions regarding distance were found to modify the verbal report of distance, whereas perceived distance, as measured by the head-motion procedure, was unchanged.

The second of the above studies (Gogel, 1981) supports the conclusion that off-sized perceptions can modify direct responses (e.g., verbal reports) to distance, without necessarily affecting perceived distance. From the head-motion 
results, there was no indication that the secondary distance process $\left(D_{c}\right)$ modified the perception of distance. On the other hand, despite the failure of the SDIH to explain the results, observers in the present study were clear and consistent in indicating that the object appeared to move in distance. It was decided, therefore, to use the head-motion procedure to examine whether this reported depth from the secondary process indeed modified perceived distance. As will be discussed, the conclusion was that optical expansion can produce substantial perceived motions in depth, as measured by the head-motion procedure, even though the perceived sizes required by Equation 2 do not occur. Under conditions of continuous optical expansion presented at a constant physical distance, secondary processes $\left(D_{c}\right.$ in Equation 3$)$ as well as primary processes ( $D^{\prime}$ in Equation 1) seem to be available to contribute to perceived distance. Considering the evidence from the past studies discussed above and from the present study, distance responses based on $D_{c}$ can be classified as either perceptual or cognitive (or perhaps some of both), depending upon the conditions of stimulation.

\section{EXPERIMENT 1}

The purpose of Experiment 1 was to determine whether the perception of size and motion in depth resulting from an optical expansion pattern located at a constant physical distance from the observer could be explained entirely by the size-distance invariance hypothesis, as expressed by Equations 1 and 2 .

\section{Method}

Observers. Six observers took part in the experiment. All had normal or corrected-to-normal vision and were naive as to the purpose of the experiment.

Apparatus. Each stimulus was a single horizontal line of variable length, presented on a video monitor (USI VM1230), at a physical distance of $45 \mathrm{~cm}$ from the observer. The line was generated by a computer (Apple IIc), and was varied in length to produce an optical expansion corresponding to a line of constant physical size moving toward and away from the observer at a constant velocity of $4 \mathrm{~cm} / \mathrm{sec}$. Three physical sizes of line, $3.0,5.0$, and $7.0 \mathrm{~cm}$ in length $\times .07 \mathrm{~cm}$ in width, were presented at different times on the monitor to provide the "far" simulated distance of the optical expansion. Each line then expanded so as to simulate movement in depth through $10.0,14.0$, or $18.0 \mathrm{~cm}$ toward the observer and then immediately contracted to return to the "far" position with this cycle presented repetitively. Thus, for each line length at the "far" distance of simulation, there were three lengths corresponding to the three near simulated distances from the optical expansion. Table 1 shows the angles $\theta_{f}$ and $\theta_{n}$ subtended at the eye at each of the three terminal simulated distances. Line width was not varied, since the variation would have been too slight to be displayed effectively. The screen was covered by 560 pixels horizontally and 192 vertically; each pixel covered approximately .03 and $.07 \mathrm{~cm}$, respectively. The brightness of the line was reduced so that no phosphor trace was discernible; the line, however, remained readily visible to the observer. Adjustments of this setting were made individually for the observer. The unused portion of the screen and the surfaces of the cubicle containing the apparatus were covered with black material. Except for the luminous lines, the experiment was conducted in darkness throughout. The observers, with their heads in a stationary chinrest to prevent lateral head movements during a trial, recorded their observations by adjusting the separation of posts mounted in a framework beneath the surface on which the monitor was placed. These posts were adjusted by touch only, with the observers using one or both hands, as needed. The posts were $6 \mathrm{~cm}$ high $\times 1 \mathrm{~cm}$ in cross section. One post was always fixed in position, $30 \mathrm{~cm}$ in front of the plane of the observer's head. Of the other two, one could be moved laterally to the right by the observer through a maximum of $25 \mathrm{~cm}$ to indicate perceived size and the other sagittally in distance through a maximum of $30 \mathrm{~cm}$ to indicate perceived depth. The observer indicated the perceived extents by adjusting the felt space between the flat inner surfaces of the fixed and the movable post. The distance between the posts was recorded by the computer through geared potentiometers attached to the posts, with the measures recorded to the nearest millimeter.

Procedure. With each of the three lines simulated to move through the same $10.0,14.0$, or $18.0 \mathrm{~cm}$ in depth, there were nine experimental conditions. The observers saw each condition three times with a random order of presentation of the resulting 27 trials. All observations were made with the right eye only, the other eye being covered by an opaque patch. On a given trial, one of the lines was first presented statically at its smallest size (its farthest simulated distance), and the observers used the posts to indicate its per-

Table 1

Results from Experiment 1

\begin{tabular}{|c|c|c|c|c|c|c|c|c|c|}
\hline \multirow{2}{*}{$\begin{array}{l}\text { Length at } \\
\text { "Far" (cm) }\end{array}$} & \multicolumn{2}{|c|}{ Visual Angle } & \multicolumn{4}{|c|}{ Dynamic $S^{\prime}$} & \multicolumn{2}{|c|}{ Predicted Depth Motion } & \multirow{2}{*}{$\begin{array}{c}d^{\prime} \text { from } \\
\text { Direct Measures }\end{array}$} \\
\hline & $\theta_{f}$ & $\theta_{n}$ & $\theta_{n} / \theta_{f}$ & $S_{f}^{\prime}$ & $S_{n}^{\prime}$ & $S_{n}^{\prime} / S_{f}^{\prime}$ & Equation 2 & Equation 4 & \\
\hline 3.0 & $\begin{array}{l}3.8 \\
3.8 \\
3.8\end{array}$ & $\begin{array}{l}4.9 \\
5.5 \\
6.3\end{array}$ & $\begin{array}{l}1.29 \\
1.45 \\
1.66\end{array}$ & $\begin{array}{l}4.2 \\
4.2 \\
4.2\end{array}$ & $\begin{array}{l}6.6 \\
7.4 \\
7.4\end{array}$ & $\begin{array}{l}1.55 \\
1.71 \\
1.74\end{array}$ & $\begin{array}{l}-13.6 \\
-12.7 \\
-3.1\end{array}$ & $\begin{array}{l}+14.3 \\
+19.7 \\
+25.3\end{array}$ & $\begin{array}{l}+6.6 \\
+8.3 \\
+12.0\end{array}$ \\
\hline 5.0 & $\begin{array}{l}6.3 \\
6.3 \\
6.3\end{array}$ & $\begin{array}{r}8.1 \\
9.2 \\
10.5\end{array}$ & $\begin{array}{l}1.29 \\
1.46 \\
1.67\end{array}$ & $\begin{array}{l}6.6 \\
6.6 \\
6.6\end{array}$ & $\begin{array}{r}9.6 \\
10.3 \\
12.2\end{array}$ & $\begin{array}{l}1.46 \\
1.60 \\
1.85\end{array}$ & $\begin{array}{l}-8.1 \\
-5.1 \\
-6.8\end{array}$ & $\begin{array}{l}+13.3 \\
+18.6 \\
+23.7\end{array}$ & $\begin{array}{l}+7.9 \\
+9.5 \\
+12.6\end{array}$ \\
\hline 7.0 & $\begin{array}{l}8.8 \\
8.8 \\
8.8\end{array}$ & $\begin{array}{l}11.3 \\
12.7 \\
14.5\end{array}$ & $\begin{array}{l}1.28 \\
1.44 \\
1.65\end{array}$ & $\begin{array}{l}8.6 \\
8.6 \\
8.6\end{array}$ & $\begin{array}{l}12.9 \\
13.8 \\
15.4\end{array}$ & $\begin{array}{l}1.49 \\
1.62 \\
1.78 \\
\end{array}$ & $\begin{array}{l}-9.2 \\
-5.5 \\
-3.9\end{array}$ & $\begin{array}{l}+12.2 \\
+17.0 \\
+21.9\end{array}$ & $\begin{array}{l}+9.3 \\
+10.5 \\
+13.4\end{array}$ \\
\hline
\end{tabular}

Note-The Subscripts $f$ and $n$ refer to the farthest and nearest distances simulated by the optical expansion pattern, physically always at $45 \mathrm{~cm}$ from the observer. $\theta_{f}$ and $\theta_{n}$ are the visual angles (in degrees) of the stimulus at the farthest and nearest simulated distances, respectively. $S_{f}^{\prime}$ and $S_{n}^{\prime}$ are the perceived sizes (in centimeters) at these simulated distances, as measured from the dynamic presentations using the laterally adjustable posts. Predicted depth motion from primary and secondary processes is found by substituting values of $D_{n}^{\prime}$ and $D_{f}^{\prime}$ obtained from Dynamic $S_{n}^{\prime}$ and $S_{f}^{\prime}$ in Equations 2 and 4, respectively. These results can be compared with the direct measure (in centimeters) obtained using the sagittally adjustable post. 
ceived (static) size. They then observed a number of repeated cycles of expansion and contraction of this line. During this dynamic phase, they were asked to indicate three characteristics of the stimulus: the perceived motion in depth, the perceived (dynamic) size at the nearest point, and the perceived (dynamic) size at the farthest point. No observer had any difficulty with the procedure, and all reported seeing both changes in size and motion in depth.

\section{Results}

The mean perceived sizes of the three lines presented statically on each trial before the start of the optical expansion (Static $S_{f}^{\prime}$ ) were 4.8,7.6, and $10.2 \mathrm{~cm}$. When the same lengths were seen during the expansion and contraction at the "far" distance of the perceived motion of each line (Dynamic $S_{f}^{\prime}$ ), the perceived sizes were 4.2, 6.6, and $8.6 \mathrm{~cm}$. These perceived lengths are larger than the physical lengths of $3.0,5.0$, and $7.0 \mathrm{~cm}$, respectively. The direction of these differences between physical and perceived length at the "far" distance of $45 \mathrm{~cm}$ was consistent with the effect expected from the specific distance tendency, which would increase the perceived distance in the direction of 2 or $3 \mathrm{~m}$ (Gogel \& Tietz, 1973). Such an increase in perceived size as a result of an increase in perceived distance is consistent with the SDIH. Also, as would be expected, perceived size at the "far" simulated distance increased with the increases in visual angle of $3.8^{\circ}, 6.3^{\circ}$, and $8.8^{\circ}$. Analysis of variance showed that this increase in perceived size with visual angle was significant across the three "far" line sizes $[F(2,10)=$ $79.03, p<.001]$, but there was no significant difference between static and dynamic judgments $[F(1,5)=6.0$, $p>.05]$. However, the trend of the data was for the static size judgments to be larger than the dynamic ones. Using the smallest "far" size in the denominator, the ratios of visual angles at the "far" simulated distance (or of physical sizes, since the physical distance was always constant) were $1.00,1.66$, and 2.32 ; the ratios of static perceived sizes were 1.00,1.56, and 2.10; and the ratios of dynamic perceived sizes were 1.00, 1.55, and 2.04. According to the SDIH, the similarity of the ratios of physical and perceived sizes indicates that the differently sized lines at the constant monitor distance were all perceived as being at essentially the same distance from the observer.

The left portion of Table 1 gives the visual angles $(\theta)$ and the average perceived sizes (Dynamic $S^{\prime}$ ) of each of the three line sizes $(3.0,5.0$, and $7.0 \mathrm{~cm})$ at the simulated far, $f$, and near, $n$, distances. It will be noted that all of the perceived size ratios are somewhat larger, not smaller, than the visual-angle ratios. According to the SDIH, such a result is inconsistent with any perceived motion in depth occurring in a direction from the far to the near simulated distance as the visual angle expands. Indeed, as shown in Figure 1E, if any perceived motion in depth were to occur with this pattern of changes in perceived size, according to the primary process expressed by the SDIH, it ought to occur in a direction opposite to that expected from optical expansion, that is, the line should appear to be more distant at the "near" than at the "far" simulated distance. This result, designated as negative, is shown in Table 1 for the predicted depth motion from Equation 2, as determined by the perceived size data.

The average " $d$ ' from Direct Measures" of perceived depth obtained from using the posts, and shown in the right column of Table 1, are in the direction expected from optical expansion. As indicated in Figure 3, the perceived motion in depth toward or away from the observer was reported to increase as the magnitude of the optical expansion increased. Also as shown in Figure 3, the magnitude of this apparent motion in depth for the same expansion ratio $\left(\theta_{n} / \theta_{f}\right)$ was greater when a large line was used at the far simulated distance rather than a small one. We presently have no explanation for this last effect, which is not predicted from either Equation 2 or Equation 4.

\section{Discussion}

This experiment has two basic findings. One is that the ratio of the perceived sizes $S_{n}^{\prime} / S_{f}^{\prime}$ of the stimulus at its extremes of expansion and contraction equaled or exceeded the ratio of retinal (visual angle) size $\theta_{n} / \theta_{f}$. An interpretation of this result in terms of the size-distance invariance hypothesis requires that the stimulus should have been perceived as remaining at the same distance as it expanded or contracted, or possibly as moving in apparent distance away from the observer as it expanded. This did not occur. Instead, according to the second basic result from the experiment, all observers reported that the stimulus clearly appeared to move toward them as it expanded and away from them as it contracted. It follows that the results are inconsistent with the size-distance invariance hypothesis as expressed by Equations 1 and 2 . They are consistent, however, with the postulation of two interacting processes: a primary process involving $S^{\prime}$ and $D^{\prime}$ that is consistent with the SDIH and a secondary process involving $S_{c}$ and $D_{c}$. The interrelation of these two processes is expressed by Equation 3 and is applied to the present experiment by Equation 4. Equation 4, rather than Equation 5, is appropriate for Experiment 1, since each trial in Experiment 1 started with an optical expansion, not an optical contraction. In the present experiment, as the object increased or decreased in size on the screen, the observer perceived it as increasing or decreasing in size, respectively, as a consequence of the primary process. As a result of this apparent expansion or contraction, the observer also perceived it as moving toward him as it appeared to increase in size and away from him as it appeared to decrease in size (the secondary process). The primary process requires no observer assumptions and agrees with the SDIH. The secondary process requires the observer to assume that the object is the same object despite its change in perceived size. Because the object changes in its off-sized appearance, it also seems to move in distance with respect to the observer, consistent with Equation 4.

According to Table 1, Equation 2 is unable to predict even the direction of apparent sagittal motion, whereas Equation 4 correctly predicts an increase in apparent depth 


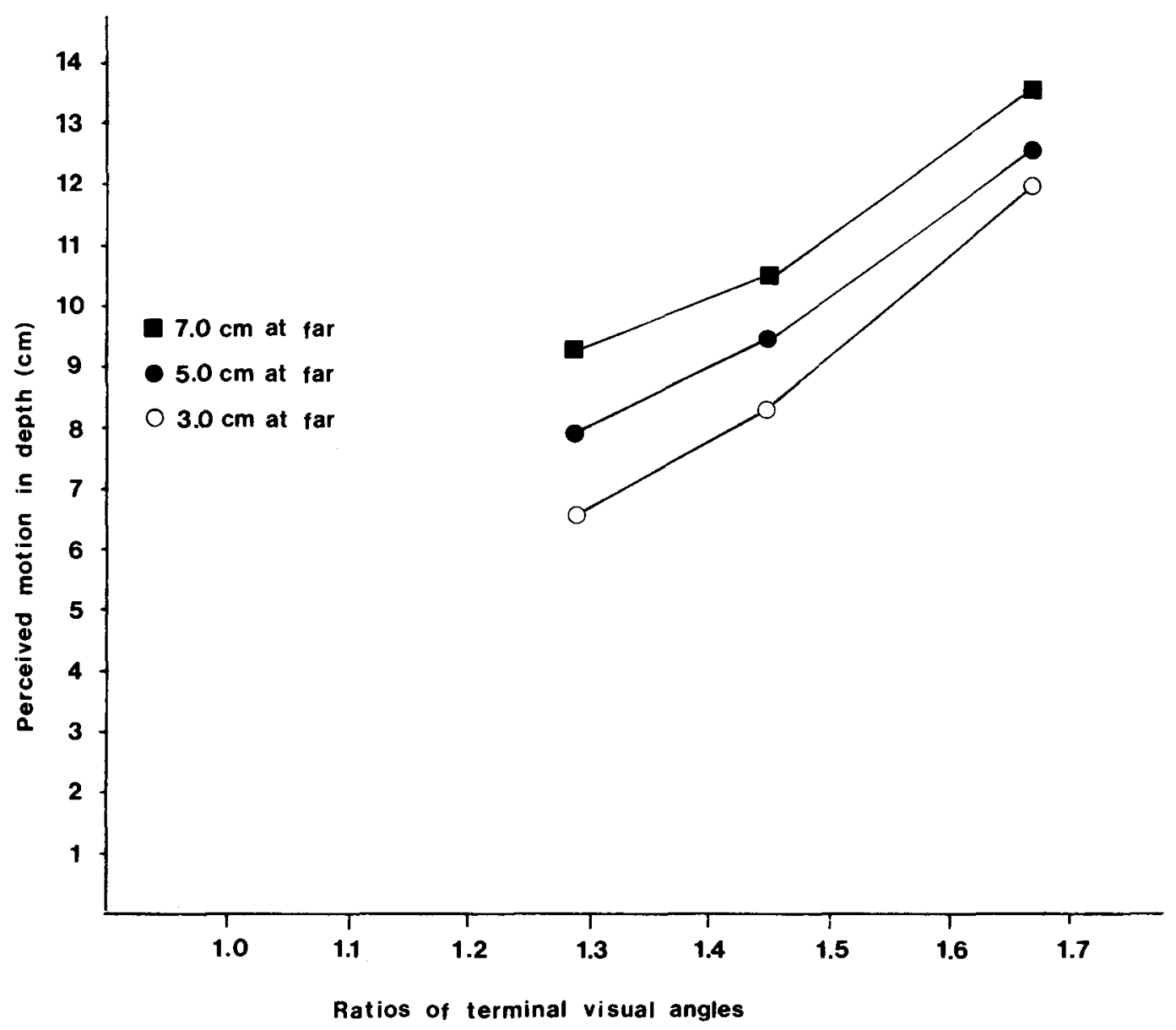

Figure 3. Relationship between perceived motion in depth $\left(d^{\prime}\right)$ and the ratio of the visual angles $\left(\theta_{n} / \theta_{f}\right)$ of the stimulus on the display monitor at the near $(n)$ and far $(f)$ simulated distances.

of motion for each increase in the magnitude of the optical expansion. However, the obtained perceived motion in depth is only about half of that predicted from Equation 4. It is likely that this can be attributed to the residual distance cues of accommodation and the specific distance tendency, which would be expected to restrict the apparent motion in depth. Clearly, these residual sources of information, if completely dominant, would result in the perception of no apparent motion in depth. On the other hand, they must be available in sufficient strength to provide the primary processes necessary to determine $S^{\prime}$ and $D^{\prime}$ in Equation 3 . It seems reasonable to expect, therefore, that, if the residual cues were in agreement with the apparent sagittal motion, as would occur if the expansion pattern on the eye were produced by the physical sagittal motion of an object of constant physical size, the result would be more in agreement with Equation 2 than was obtained in the present experiment.

\section{EXPERIMENT 2}

The purpose of Experiment 2 was to test further the validity of the distinction between primary processes (Equa- tions 1 and 2) and secondary processes (Equations 3, 4, and 5). Experiment 2 measured perceived size, perceived motion in depth, and perceived lateral motion of the stimulus concomitant with a lateral motion of the head (the head-motion procedure) under a number of conditions. The reason for using the head-motion procedure was to determine whether the apparent sagittal motion reported in Experiment 1 was actually a perceived, and not a cognitive, motion in depth. If it can be shown from the present research that the secondary process can result in perceived sagittal motion, this, together with the results of previous research (Gogel, 1976, 1981), will permit the conclusion that the secondary process can contribute to a range of distance responses extending from perceived to cognitive distance.

\section{Method}

Five conditions were used in Experiment 2. In all of these, nothing was visible to the observer except the stimulus object, with the remainder of the visual field being kept dark. Condition 1 provided an instance of Emmert's law. A line subtending a constant visual angle was viewed with changing convergence. In Condition 2 , a line of changing visual angle was viewed with a constant convergence. In Condition 3, the simulated motions in depth from con- 
vergence and changing visual angle (optical expansion) were in agreement. In Condition 4, they were opposed. Condition 5 was the same as Condition 1 except that a point of light, rather than a line, was viewed with changing convergence.

Observers. Ten observers took part in the experiment; 3 of them had been observers in Experiment 1. All had normal vision without optical correction, and all scored above $80 \%$ on the Keystone MultiStereo Test. Two additional observers who satisfied these requirements were dropped from the experiment, in one case because of an inability to maintain binocular fusion and in the other because of difficulty experienced in judging apparent concomitant motion.

Apparatus. The display system described for Experiment 1 was modified to permit the control of binocular vergence as well as the physical size of the stimuli. Again, the stimulus (in this experiment a vertical line) was always at a constant distance of $45 \mathrm{~cm}$ from the observer. The right and left halves of the monitor screen were covered by a sheet of polarizing material (Polaroid HN22 $\times 0.035$ ) with a $90^{\circ}$ difference between their orientations. Two more pieces of the same material were mounted in a holder attached to the observer's chinrest; these were oriented so that the left eye viewed only the left half of the screen and the right eye only the right half. Thus, different values of convergence could be produced by varying the horizontal position of the paired vertical-line stimuli (one line on each half of the screen) from a convergence value equal to the physical distance of the screen $(45 \mathrm{~cm})$ to a maximum of about $100 \mathrm{~cm}$. The physical length of this binocularly viewed vertical line similarly could be varied so as to correspond to an object of constant physical size moving in depth between near and far simulated distances equal to the changes in simulated distance specified by convergence. The Polaroids at the observation position were attached to a chinrest which also contained a wooden bitebar. The observer could move the chinrest, with its attachments, left and right on a track, so that the dichoptic viewing of the stimulus was maintained as the head was moved laterally. The extent of lateral motion of the head was constrained by stops to be through $13 \mathrm{~cm}$ $(6.5 \mathrm{~cm}$ left and $6.5 \mathrm{~cm}$ right). The adjustable posts described above were again used to obtain reports of perceived size and perceived movement in depth. Unlike Experiment 1, the lateral adjustment of the posts was used to indicate the perceived vertical size of the stimuli. The observers did not report any difficulty in making this adjustment.

Procedure. The five conditions in the experiment are summarized in Table 2. In Condition 1, the physical size of the stimulus was constant at $6.4^{\circ}$, but the convergence was varied between values corresponding to distances from the observer of 80 and $50 \mathrm{~cm}$. The interpupillary distance of each observer was measured prior to the experiment, and this value was used in the computer program that controlled the position of the stimulus on the monitor to produce convergence values corresponding to the required distances from the observer. In Condition 2, the convergence was constant at $80 \mathrm{~cm}$, and the visual angle of the vertical line was varied between $6.4^{\circ}$ and $10.2^{\circ}$, corresponding to a constant-sized object $9.0 \mathrm{~cm}$ in length moving in distance between 80 and $50 \mathrm{~cm}$ at a constant velocity of $12 \mathrm{~cm} / \mathrm{sec}$. In Condition 3 , both convergence and size were altered so as to simulate the same $80-$ to- 50 -cm change in dis-

Table 2

Description of Conditions in Experiment 2

\begin{tabular}{ccll}
\hline Condition & Stimulus & $\begin{array}{l}\text { Convergence } \\
\text { Distance }(\mathrm{cm})\end{array}$ & \multicolumn{1}{c}{ Size } \\
\hline 1 & line & varied, 80-50 & constant, 6.4 \\
2 & line & constant, 80 & varied, $6.4^{\circ}-10.2^{\circ}$ \\
3 & line & varied, 80-50 & varied, $6.4^{\circ}-10.2^{\circ}$ \\
4 & line & varied, 50-80 & varied, 6.4 $-10.2^{\circ}$ \\
5 & dot & varied, 80-50 & no variation \\
\hline
\end{tabular}

Note-Variations in size or convergence distance were continuous between the limits shown with the stimulus always at $45 \mathrm{~cm}$ from the observer. tance. In Condition 4, whenever convergence was changed in one direction, size was altered in the other. Thus, when convergence varied to simulate a change from 50 to $80 \mathrm{~cm}$, the optical expansion simulated a change from $80 \mathrm{~cm}\left(6.4^{\circ}\right)$ to $50 \mathrm{~cm}\left(10.2^{\circ}\right)$, with these values reversed repetitively. Condition 5 involved only convergence changes, with the stimulus consisting of two dots, one to each eye, to produce a binocularly fused single point. This point was formed by illumination of a single screen pixel. All variations in the parameters of simulated depth were made over the same time interval, so that a change from "far" to "near" or from "near" to "far," however determined, occupied $2.5 \mathrm{sec}$. For all presentations of the stimuli, a pause of $3 \mathrm{sec}$ was introduced at the near and far simulated distances to enable observers to make lateral head movements. This duration was sufficient to permit two to three head excursions, which observers found adequate for judging the apparent concomitant motion of the stimulus. Each condition was seen four times by each observer, twice starting from the near simulated distance and twice from the far simulated distance, with the order randomized over presentations. Throughout the experiment, all judgments always were made while the head was moving to ensure that any influence on perceived distance of absolute motion parallax from the head motion was the same in all observations. On a given trial, the observer first observed the static stimulus and made several lateral head movements to judge the extent to which the stimulus appeared to move concomitantly with the head. This extent was then indicated by the observer's separation of the laterally movable posts. The procedure was then repeated for a static verticalsize judgment, again while head movements were being made. The stimulus was then made to undergo the appropriate dynamic changes, and the observers were asked to judge the perceived near or far vertical size, the perceived near or far concomitant motion, and the perceived extent of the motion in depth. All judgments, including those of apparent concomitant motion, were made at the near and far terminal positions of the simulated motion in depth, and the different judgments were obtained in a random order on different trials. To avoid fatigue, the experiment was conducted in two sessions, separated by a rest interval of 20-60 min.

\section{Results}

The results of the experiment are summarized in $\mathrm{Ta}$ bles 3 and 4 . The upper half of Table 3 shows the average settings of perceived size $\left(S^{\prime}\right)$ and lateral motion $\left(W^{\prime}\right)$ concomitant with head motion obtained for each condition using the "near" $(n)$ and "far" $(f)$ simulated distances from static (discrete) and dynamic (continuously varying) stimulation. As shown, all of the obtained values of $W^{\prime}$ are negative, indicating that the apparent concomitant motion of the line stimulus was in a direction opposite to that of the head motion. The less negative the score, the closer to the observer the stimulus appeared to be. In the case of Condition 4, the "near" and "far" designations are given to the large and small angular sizes of the stimulus, respectively. This is arbitrary, since the simulated depth motion from convergence in this condition was in the opposite direction. The average perceived distances $D_{f}^{\prime}$ and $D_{n}^{\prime}$, computed from Equations 1 and 6 using the $S^{\prime}$ and $W^{\prime}$ values shown in the upper half of Table 3, are given in the lower half of Table 3 . Since all values of $D_{f}^{\prime}$, whether calculated from $S^{\prime}$ or $W^{\prime}$, were larger than $45 \mathrm{~cm}$, it is evident that the perceived distance of the "far" stimulus exceeded the physical distance of the stimulus from the observer. Table 4 lists the average perceived motions in depth $\left(d^{\prime}\right)$ as determined from the $S^{\prime}$ values using Equation 2, or from the $W^{\prime}$ values using 
Table 3

Results (in Centimeters) from Experiment 2

\begin{tabular}{|c|c|c|c|c|c|c|}
\hline \multirow[b]{3}{*}{ Condition } & \multicolumn{6}{|c|}{ Perceived Size $S^{\prime}$} \\
\hline & \multicolumn{3}{|c|}{ Static $S^{\prime}$} & \multicolumn{3}{|c|}{ Dynamic $S^{\prime}$} \\
\hline & $S_{f}^{\prime}$ & $S_{n}^{\prime}$ & $S_{n}^{\prime} / S_{f}^{\prime}$ & $S_{f}^{\prime}$ & $S_{n}^{\prime}$ & $S_{n}^{\prime} / S_{f}^{\prime}$ \\
\hline 1 & 7.9 & 6.7 & .86 & 7.4 & 7.2 & .96 \\
\hline 2 & 7.4 & 11.7 & 1.59 & 7.5 & 11.4 & 1.54 \\
\hline 3 & 8.1 & 10.3 & 1.29 & 7.6 & 10.1 & 1.36 \\
\hline 4 & 7.0 & 11.5 & 1.66 & 7.2 & 11.2 & 1.59 \\
\hline
\end{tabular}

Perceived Concomitant Motion $W^{\prime}$

\begin{tabular}{|c|c|c|c|}
\hline \multicolumn{2}{|c|}{ Static $W^{\prime}$} & \multicolumn{2}{|c|}{ Dynamic $W^{\prime}$} \\
\hline$W_{f}^{\prime}$ & $W_{n}^{\prime}$ & $W_{f}^{\prime}$ & $W_{n}^{\prime}$ \\
\hline $\begin{array}{l}-7.2 \\
-7.2 \\
-7.9 \\
-6.8 \\
-6.5\end{array}$ & $\begin{array}{l}-5.7 \\
-7.5 \\
-6.3 \\
-7.4 \\
-5.6\end{array}$ & $\begin{array}{l}-7.1 \\
-7.8 \\
-8.4 \\
-7.1 \\
-7.8\end{array}$ & $\begin{array}{l}-5.7 \\
-7.0 \\
-6.3 \\
-7.4 \\
-5.5\end{array}$ \\
\hline
\end{tabular}

$D^{\prime}$ from $S^{\prime} / \tan \theta$ (Equation 1)

\begin{tabular}{|c|c|c|c|}
\hline \multicolumn{2}{|c|}{ From Static $S^{\prime}$} & \multicolumn{2}{|c|}{ From Dynamic $S^{\prime}$} \\
\hline$D_{f}^{\prime}$ & $D_{n}^{\prime}$ & $D_{f}^{\prime}$ & $D_{n}^{\prime}$ \\
\hline 70.5 & 59.6 & 66.1 & 63.7 \\
\hline 66.1 & 65.0 & 66.6 & 63.4 \\
\hline 72.5 & 57.1 & 67.3 & 56.3 \\
\hline 62.1 & 63.8 & 63.7 & 62.3 \\
\hline
\end{tabular}

$D^{\prime}$ from $D\left(K-W^{\prime}\right) / K$ (Equation 6)

\begin{tabular}{ccccc}
\hline \multicolumn{2}{c}{ From } & Static $W^{\prime}$ & & \multicolumn{2}{c}{ From Dynamic $W^{\prime}$} \\
\cline { 5 - 5 }$D_{f}^{\prime}$ & $D_{n}^{\prime}$ & & $D_{f}^{\prime}$ & $D_{n}^{\prime}$ \\
\hline 70.0 & 64.6 & 69.7 & 64.7 \\
70.0 & 71.0 & 71.9 & 69.1 \\
72.5 & 65.6 & 74.1 & 66.8 \\
68.5 & 70.6 & 69.5 & 70.7 \\
67.5 & 64.3 & 72.0 & 64.1 \\
\hline
\end{tabular}

Note-The $S^{\prime}$ notation is the same as that used in Table 1. $W^{\prime}$ refers to apparent motion concomitant with a motion of the head.

Equation 7, or as measured directly by the observer's adjustment of the depth between the posts (" $d$ ' from Direct Measures"). The $d$ ' values in Table 4, calculated from the Dynamic $S^{\prime}$ presentations, represent the predictions of depth motion from the SDIH (Equation 2), and the $d^{\prime}$ values from the Dynamic $W^{\prime}$ data indicate the amounts of motions in depth calculated from the head-motion procedure (Equation 7) that can be classified as perceptual. Again, in Condition 4, a motion in depth is listed as positive if it is consistent in direction with optical expansion, whether or not it is consistent with convergence.
Conditions 1 and 5. Consider Condition 1, an instance of Emmert's law, in which the convergence to a line of constant visual angle is varied. In this situation, it is expected that the convergence changes will result in changes in $D^{\prime}$ and, according to the SDIH, since $\theta$ is constant, that $S^{\prime}$ will vary directly with $D^{\prime}$ (Irwin, 1969; King \& Gruber, 1962; Price, 1961; Weintraub \& Gardner, 1970). However, the secondary process, $D_{c}$, is present, and it is not in agreement with the perception of distance from the primary process. For example, as the perceived size increases, with increasing perceived distance, the stimulus will be seen as an increasingly large off-sized object relative to the prior presentations. Expressed in terms of Equation 3, at the near convergence $D_{c}$ (near) $=D_{n}^{\prime}\left(S_{c} / S_{n}^{\prime}\right)$. Since $S_{c}=S_{n}^{\prime}, D_{c}=D_{n}^{\prime}$. At the far convergence $D_{c}($ far $)$ $=D_{f}^{\prime}\left(S_{c} / S_{f}\right)$, where $S_{c}$ again equals $S_{n}^{\prime}$. But $S_{n}^{\prime}=\theta_{n} D_{n}^{\prime}$ and $S_{f}^{\prime}=\theta_{f} D_{f}^{\prime}$ from Equation 1 . Therefore, at the far convergence, $D_{c}($ far $)=D_{f}^{\prime}\left(\theta_{n} D_{n}^{\prime} / \theta_{f} D_{f}^{\prime}\right)=D_{n}^{\prime}\left(\theta_{n} / \theta_{f}\right)$ or, since $\theta_{n}=\theta_{f}$ in this case, $D_{c}$ at both the near and far convergence equals $D_{n}^{\prime}$. That is, according to the secondary process, $d_{c}=0$. In other words, throughout the convergence change, the secondary distance effect, $D_{c}$, is constant, in opposition to the primary effect, $D^{\prime}$, provided by the changing convergence.

In this or any other situation in which the primary and secondary processes are not in agreement, the observer has two opposing sources of information regarding size and distance. One of these, the primary process, involves $S^{\prime}$ and $D^{\prime}$. The other, the secondary process, involves $S_{c}$ and $D_{c}$. The response to size can be determined by some weighted average of $S_{c}$ and $S^{\prime}$, and the response to distance by some weighted average of $D_{c}$ and $D^{\prime}$ (see Gogel, 1976). It follows that the perception of sagittal motion is likely to be less in the case involving an extended object of constant visual size (Emmert's law) than for the same convergence changes using a point stimulus. Thus, $d^{\prime}$ should be less in Condition 1 than in Condition 5. As shown in Table 4, this was the result obtained. The perceived motion in depth, either as measured by the headmotion procedure or as measured directly by using the posts was less for Condition $1(5.0$ and $4.8 \mathrm{~cm})$ than for Condition $5(7.9$ and $7.8 \mathrm{~cm})$. The difference between these conditions using the posts $(7.8-4.8 \mathrm{~cm})$ was significant $[t(7)=3.65, p<.05]$, whereas the similar difference using the head-motion procedure $(7.9-5.0 \mathrm{~cm})$ was not significant $[t(7)=1.45, p>.05]$. Thus, the

Table 4

Results (in Centimeters) from Experiment 2: Apparent Motions in Depth $\left(d^{\prime}\right)$ Computed Indirectly from Either Perceived Size $\left(S^{\prime}\right)$, using Equation 2, or Concomitant Motion $\left(W^{\prime}\right)$, using Equation 7 , and Values Obtained from Direct Measurement Using the Posts

\begin{tabular}{cccccc}
\hline Condition & $\begin{array}{c}d^{\prime} \text { from } \\
\text { Static } S^{\prime}\end{array}$ & $\begin{array}{c}d^{\prime} \text { from } \\
\text { Dynamic } S^{\prime}\end{array}$ & $\begin{array}{c}d^{\prime} \text { from } \\
\text { Static } W^{\prime}\end{array}$ & $\begin{array}{c}d^{\prime} \text { from } \\
\text { Dynamic } W^{\prime}\end{array}$ & $\begin{array}{c}d^{\prime} \text { from } \\
\text { Direct Measures }\end{array}$ \\
\hline 1 & +10.9 & +2.4 & +5.4 & +5.0 & +4.8 \\
2 & +1.1 & +3.2 & -1.0 & +2.8 & +9.0 \\
3 & +15.4 & +11.0 & +5.9 & +7.3 & +11.5 \\
4 & -1.7 & +1.3 & -2.1 & -1.2 & +10.1 \\
5 & & & +3.2 & +7.9 & +7.8 \\
\hline
\end{tabular}

Note-Negative values indicate that the computed "near" distance was farther than the computed "far" distance. See text for details of calculations. 
results, although not completely definitive, are consistent with the conclusion that the factor $S_{c} / S^{\prime}$ reduced the apparent depth generated from convergence in the application of Emmert's law in Condition 1. One seeming anomaly in the data from Condition 1, as shown in Table 3 , is that the measured size change between the "far" and "near" simulated distances was greater for the static presentations $(7.9-6.7 \mathrm{~cm})$ than for the dynamic presentations $(7.4-7.2 \mathrm{~cm})$. In the static presentations, only the primary size process $\left(S^{\prime}\right)$ was available. In the dynamic presentations, both $S^{\prime}$ and $S_{c}$ were available, with $S_{c}$ reflecting the observer assumption that the size of the object presented initially remained the actual size of the object despite its changing apparent size. Possibly the size response in the dynamic situation was a compromise between these discrepant sources of size information.

Condition 2. Condition 2 was similar to Experiment 1 except that only one change in line length $\left(6.4^{\circ}\right.$ to $\left.10.2^{\circ}\right)$ was used and convergence, in addition to accommodation, provided oculomotor cues of a constant distance. The ratio of perceived dynamic sizes obtained from Condition 2 at the near and far simulated distances (1.54) in Table 3 is very similar to the ratio of the retinal sizes of the line (1.59). It follows from this result and the SDIH that little motion in apparent depth $\left(d^{\prime}\right)$ should have occurred. However, as shown in Table $4,9.0 \mathrm{~cm}$ of average apparent sagittal motion was present, as measured directly by using the posts, with this value statistically significant $[t(7)=7.87, p<.01]$. This result, like that of Experiment 1, can be explained by the secondary process described in Equation 3. The question of importance is whether the use of the head-motion procedure indicates that this measured motion in depth was perceptual or cognitive. In order to conclude that any portion of this result from secondary processes was perceptual, the apparent sagittal motion computed from Dynamic $W^{\prime}(2.8 \mathrm{~cm}$ in Table 4) must be greater than that which can be attributed to the primary process as measured by Dynamic $S^{\prime}$ (3.2 $\mathrm{cm}$ in Table 4). Although the 2.8 difference between $D_{f}^{\prime}$ and $D_{n}^{\prime}$ is statistically significant $[t(7)=2.86, p<.05]$ whereas the $3.2 \mathrm{~cm}$ value is not significant, the similarity of these results raises doubts as to whether the direct measure of apparent motion in depth obtained in Condition 2 can be classified as perceptual.

Conditions 3 and 4 . Condition 3, in which changes in convergence and visual angle (optical expansion) simulated apparent motions in the same direction, as expected gave rise to a large apparent motion in depth. This is reflected in all five measures of apparent depth motion $\left(d^{\prime}\right)$ listed in Table 4, including that obtained from the head-motion procedure. Clearly, the apparent motion in depth from this condition was perceptual. But equally clearly, since it occurred for the static as well as the dynamic presentations, it can be explained by the SDIH, and secondary processes are not required. In Condition 4 , the convergence changes and optical expansion were in opposite directions. A plus sign for the results from Condi- tion 4 means that the observer's responses of "near" and "far" 'were determined by optical expansion, not convergence. Thus, the positive values found in Table 4 for Condition 4 indicate that optical expansion mainly determined the direction of the reported motion in depth. Since the ratio of perceived dynamic sizes in Table 3 , Condition 4 (1.59) was the same as the ratio of retinal sizes, the substantial direct measure of sagittal motion $(+10.1 \mathrm{~cm})$ found in Table 4, Condition 4 was due to secondary, not primary, distance responses from the optical expansion pattern. However, a matching value of $d^{\prime}$ in Table 4 is not found for Condition 4 from the head-motion procedure with the Dynamic $W^{\prime}$ condition. The result $(-1.2 \mathrm{~cm})$ is both small and in a direction opposite to that from the direct measure of $d^{\prime}$. It seems that under conditions in which convergence and optical expansion vary in opposite directions, a perceived motion in depth does not occur consistent with either cue, indicating, in this case, that their opposite effects on the response are equal in magnitude.

In summary, the results of Experiment 2 substantiate the basic finding of Experiment 1, that the SDIH cannot explain the direct measures of perceived depth obtained from optical expansion. But it has not been demonstrated unequivocally that the direct measures of perceived depth obtained from the post adjustments were indeed perceptual, as could have been concluded in Condition 2 if similar results had been obtained from the head-motion procedure. The small $d^{\prime}(2.8 \mathrm{~cm})$, as measured by the head-motion procedure in Condition 2 , could be explained by the $d^{\prime}(3.2)$ as computed from the changes in perceived size using Equation 2 of the SDIH. On the other hand, apparent depth, as measured by the head-motion procedure, was considerably reduced (from $+7.3 \mathrm{~cm}$ to $-1.2 \mathrm{~cm}$ ) when the optical expansion pattern, rather than agreeing with the convergence changes (Condition 3), was in opposition to the convergence changes (Condition 4). This difference is statistically significant $[t(7)=3.03$, $p<.05]$. It indicates that the optical expansion pattern was able to modify significantly the perceived depth associated with a constant change in convergence. It is difficult to see how this could have occurred if the optical expansion pattern were not providing an opposing perception of depth. Nevertheless, since the test of the perceptual modification of $d^{\prime}$, as measured with the head-motion procedure in Condition 2, was equivocal, Condition 2 was repeated, with some modifications, in Experiment 3.

\section{EXPERIMENT 3}

Experiment 3 was similar to Condition 2 of Experiment 2 and had the same purpose. This was to determine, using the head-motion procedure, whether the reported depth from the optical expansion pattern was cognitive or perceptual. 
Table 5

Results (in Centimeters) from Experiment 3: Average Perceived Sizes $\left(S^{\prime}\right)$, Perceived Concomitant Motions $\left(W^{\prime}\right)$,* and Perceived Distances $\left(D^{\prime}\right)$ Computed from $S^{\prime}$ (Equation 1) and from $W^{\prime}$ (Equation 6)

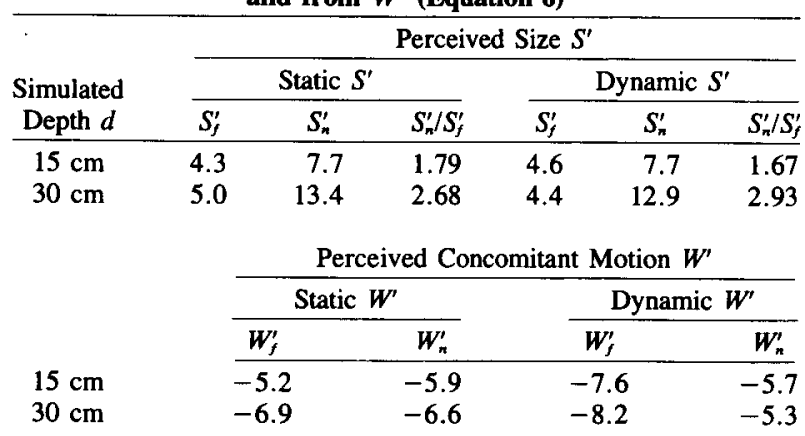

$D^{\prime}$ from $S^{\prime} / \tan \theta$ (Equation 1)

\begin{tabular}{lccccc} 
& \multicolumn{2}{c}{ From Static $S^{\prime}$} & & \multicolumn{2}{c}{ From Dynamic $S^{\prime}$} \\
\cline { 2 - 3 } & \multicolumn{1}{c}{$D_{f}^{\prime}$} & $D_{n}^{\prime}$ & & $D_{f}^{\prime}$ & $D_{n}^{\prime}$ \\
\cline { 2 - 3 } $15 \mathrm{~cm}$ & 38.9 & 46.0 & & 41.7 & 46.0 \\
$30 \mathrm{~cm}$ & 45.3 & 40.3 & & 39.9 & 38.8
\end{tabular}

$D^{\prime}$ from $D\left(K-W^{\prime}\right) / K$ (Equation 6)

\begin{tabular}{ccccc}
\multicolumn{2}{c}{ From Static $W^{\prime}$} & & \multicolumn{2}{c}{ From Dynamic $W^{\prime}$} \\
\cline { 5 - 5 }$D_{f}^{\prime}$ & $D_{n}^{\prime}$ & & $D_{f}^{\prime}$ & $D_{n}^{\prime}$ \\
\hline 63.0 & 65.4 & 71.3 & 64.7 \\
68.9 & 67.8 & & 73.4 & 63.3
\end{tabular}

$30 \mathrm{~cm}$ Note-*The negative values of $W^{\prime}$ indicate that the apparent lateral motion of the test stimulus concomitant with the lateral motion of the head was in a direction opposite to the head motion. As shown in the two lower portions of the table, this means that the apparent distance $\left(D^{\prime}\right)$ of the test object, as measured by the head-motion procedure, was greater than the physical distance of $\mathbf{4 5} \mathrm{cm}$ throughout the optical expansion.

\section{Method}

Observers. Six observers took part in the experiment; 2 of them had participated in one or both of the previous experiments.

Apparatus. The apparatus was the same as that used in Condition 2 of Experiment 2, except that the polarizing material was not used, since the viewing always was monocular. The stimulus line again was presented on a monitor that was at a constant distance of $45 \mathrm{~cm}$ from the observer. The display consisted of a vertical, luminous line, which could be varied in length from $5 \mathrm{~cm}$ (a visual angle of $\left.6.3^{\circ}\right)$ at the far simulated distance to either $7.5 \mathrm{~cm}\left(9.5^{\circ}\right)$ or $15 \mathrm{~cm}\left(18.4^{\circ}\right)$ at the near simulated distances. This corresponded to simulated motions in depth from the monitor surface toward the observer of 15 or $30 \mathrm{~cm}$, respectively, with a constant simulated velocity of $4 \mathrm{~cm} / \mathrm{sec}$. Except for the luminous line, the visual field was entirely dark.

Procedure. On each trial, the observers were first shown the line statically at either its near or far size. They then made lateral head movements and, using the laterally adjustable posts, indicated the perceived vertical length (size) and the perceived lateral motion of the line concomitant with the head motion. Cycles of expansion and contraction of physical size were then started with a pause of
$3 \mathrm{sec}$ at the simulated near and far distances. During these pauses, the observers made lateral head motions and reported in random order, using the posts, the perceived size and perceived concomitant motion at both the far and near simulated distances and the extent of motion in depth. The observers were presented with each of the simulated motions in depth four times, starting twice from the near and twice from the far simulated distance. All observations were monocular using the right eye.

\section{Results}

The average results from Experiment 3 are shown in Tables 5 and 6 . The upper half of Table 5 shows the apparent size $\left(S^{\prime}\right)$ and apparent concomitant motion $\left(W^{\prime}\right)$ for both the static presentations, in which a line was shown discretely, and the dynamic presentations, in which the line was continuously varied in size to simulate an approaching or receding object. For the smaller $(15-\mathrm{cm})$ simulated motion in depth, the ratio of $S^{\prime}$ values at the near and far simulated distances was 1.79 for Static $S^{\prime}$ and 1.67 for Dynamic $S^{\prime}$, with the ratio of the visual angles $\left(\theta_{n} / \theta_{f}\right) 1.51$. For the larger $(30-\mathrm{cm})$ simulated motion in depth, the corresponding ratios were 2.68, 2.93, and 2.92, respectively. According to the Dynamic $S^{\prime}$ ratios and the prediction from the SDIH, the apparent motion in depth should have been small or negative, as shown by the $-5.3-$ and $+1.1-\mathrm{cm}$ Dynamic $S^{\prime}$ values of Table 6 . But, in disagreement with the SDIH, the average direct measures of $d^{\prime}$ in Table 6 showed that +5.4 and $+10.1 \mathrm{~cm}$ of apparent motion in depth occurred for the small and large simulated motions in depth, respectively. Of particular interest is the fact that the $d^{\prime}$ s calculated from "Dynamic $W$ " in Table 6 are quite similar to the results from " $d$ ' Direct Measures" using the posts. All 6 observers gave positive $d^{\prime}$ results as calculated both from the $W^{\prime}$ data and from the direct measures of $d^{\prime}$ for both the $15-$ and $30-\mathrm{cm}$ simulated motions in depth. According to the head-motion criterion, in this experiment, the substantial, direct measures of motion in depth generated by the optical expansion pattern, and not predictable from the SDIH, were perceptual, not cognitive. It follows that the secondary process responsible for $D_{c}$ can, under the appropriate conditions, result in a perceptual response of distance. Both the present research and the previous research show that $D_{c}$, as measured in a psychophysical experiment, can be either perceptual or cognitive, depending upon the circumstances. Continuous changes in image size can result in a perceived motion in depth even though the reported size change is inconsistent with the primary process as specified by the SDIH.

The robust and similar measures of perceived depth obtained from the head-motion (Dynamic $W^{\prime}$ ) and from direct measures (sagittal post adjustments) have an addi-

Table 6

Results (in Centimeters) from Experiment 3:

Values of Perceived Depth $\left(d^{\prime}\right)$ as Calculated from $S^{\prime}$ Data Using Equation 2 or from $W^{\prime}$ Data Using Equation 7

\begin{tabular}{cccccc}
\hline $\begin{array}{c}\text { Simulated } \\
\text { Depth } d\end{array}$ & $\begin{array}{c}d^{\prime} \text { from } \\
\text { Static } S^{\prime}\end{array}$ & $\begin{array}{c}d^{\prime} \text { from } \\
\text { Dynamic } S^{\prime}\end{array}$ & $\begin{array}{c}d^{\prime} \text { from } \\
\text { Static } W^{\prime}\end{array}$ & $\begin{array}{c}d^{\prime} \text { from } \\
\text { Dynamic } W^{\prime}\end{array}$ & $\begin{array}{c}d^{\prime} \text { from } \\
\text { Direct Measures }\end{array}$ \\
\hline $15 \mathrm{~cm}$ & -7.1 & -5.3 & -2.4 & +6.6 & +5.4 \\
$30 \mathrm{~cm}$ & +5.0 & +1.1 & +1.1 & +10.1 & +10.1 \\
\hline
\end{tabular}


tional implication. They provide evidence that the perceived position of the line stimulus remained substantially unchanged at the near and far simulated distances during the 3-sec pauses rather than regressing to the perceived distance of the monitor. If a reduction in perceived depth had occurred as a consequence of the pauses, this would have been reflected in the Dynamic $W^{\prime}$ as well as the Dynamic $S^{\prime}$ measures. Since this did not occur, the obtained proportionality between ratios of Dynamic $S^{\prime}$ and ratios of visual angle is, indeed, counter to the SDIH and cannot be explained by postulating a loss in perceived depth during the 3-sec pauses.

From the above experiments, the perceptions associated with optical expansion or contraction can be explained by the two-process theory. The primary process is specified by Equation 1 and the secondary process by Equation 3 . As shown in Experiments 1 and 3, in which $\theta_{n} / \theta_{f}$ was varied, the effect of $\theta_{n} / \theta_{f}$ on the results is in agreement with Equation 4 or Equation 5 , in that the larger $\theta_{n} / \theta_{f}$ consistently produced the larger perceived motion in depth. However, the obtained apparent motions in depth were not as large as predicted. In the present experiment, according to either Equation 4 or Equation 5, the ratio of large $d_{c} /$ small $d_{c}$ should have been 3.76 , whereas the obtained ratios were 1.87 from "Direct Measures"' and 1.53 from Dynamic $W^{\prime}$ (using the data of Table 6). Again, a likely explanation of these quantitative discrepancies from the predicted values is that the residual cues (accommodation and the specific distance tendency), indicating that the stimulus was always at a constant distance, restricted the magnitude of the reported motion in depth. In other words, $D^{\prime}$ and $D_{c}$ were in conflict, with the final perceived depth being a compromise between these two sources of information. An additional factor which, according to Equation 4 or Equation 5, is expected to modify the magnitude of the perceived motion in depth from optical expansion is the perceived distance, $D^{\prime}$, of the expansion pattern. This latter factor was examined in Experiment 4.

\section{EXPERIMENT 4}

The perceived distance of the optical expansion pattern in Experiment 4 was varied by using the equidistance tendency. This tendency is that, in the absence or reduction of effective cues of distance, objects will tend to appear at the same distance (equidistant) or near the same distance, with the strength of this tendency being inversely related to the directional separation of the objects (Gogel, 1965). It follows that if an optical expansion pattern with few, if any, cues as to its distance from the observer is viewed against a visible background containing adequate cues of distance, the expansion pattern at its starting distance will appear to be near or at the distance of the background. An illustration of the equidistance tendency is the situation in which a visual afterimage appears to be projected near or on a background wall. If the perceived distance of the wall is changed by the observer's moving toward or away from it, the perceived distance of the ex- pansion pattern and its perceived size will also be changed. With the terminal angles of an optical expansion pattern held constant and $D^{\prime}$ of the expansion pattern increased by the equidistance tendency in this manner, $d_{c}$ (according to Equation 4 or Equation 5) is also expected to increase. This indicates the basic procedure used in the present experiment to test these equations.

Also, it can be argued that the inability of the SDIH to explain the results of the previous experiments was in some way due to the use of a single horizontal or vertical line as the stimulus. Although, in principle, the SDIH should apply to any object, an extended two-dimensional object might be expected to be a more effective optical expansion pattern (see Johansson, 1964; Noguchi \& Taya, 1981 ) and, thus, to be more effective in producing a perception of constant size. Accordingly, in Experiment 4, the perceived motion in depth was measured for identical optical expansions using either a line or a rectangle, with these objects viewed at three different apparent distances.

\section{Method}

Observers. Six observers took part in the experiment. All had normal or corrected-to-normal vision. Four of the observers had taken part in one or more of the previous experiments.

Apparatus. This experiment was conducted in an alley different from that used in the previous experiments. The alley was $40 \mathrm{~cm}$ wide and $90 \mathrm{~cm}$ high. It was lined with a black material that was printed with a pattern of white disks (polka dots) and illuminated by an overhead fluorescent light. The end of the alley consisted of a movable board, $82 \mathrm{~cm}$ high $\times 40 \mathrm{~cm}$ wide, presented perpendicularly to the observer's line of sight. This board, which was covered with a coarse-textured off-white material and could be placed at varying distances from the observer, formed a vertical background against which the expansion stimuli were seen. The alley was observed through an aperture, $22 \mathrm{~cm}$ wide $\times 4 \mathrm{~cm}$ high, that could be closed by means of a manually operated shutter. With their heads on a stationary chinrest, the observers viewed the alley binocularly through polarizing filters mounted in a holder attached to the chinrest. There were two filters, one in front of the left eye and one in front of the right, with their directions of polarization at $90^{\circ}$. The stimulus was generated by a microcomputer (Commodore 64) and displayed on a black-and-white video monitor. Each pixel on the screen was approximately $.05 \mathrm{~cm}$ wide $\times .08 \mathrm{~cm}$ high; the resolution was 320 pixels horizontally $\times 200$ pixels vertically. The monitor was placed in an adjacent parallel alley in darkness, at a distance of $105 \mathrm{~cm}$ from the observer's eyes, and the stimulus on the monitor was made to appear superimposed upon the background in the illuminated alley by means of first-surface mirrors. A polarizing filter in the same orientation as that in front of the observer's right eye was mounted on the monitor, so that the line or outline rectangle was seen monocularly with the right eye only. Under these conditions, the luminous horizontal line or outline rectangle appeared to be suspended in the alley at approximately the distance of the background. The size of the object could be varied on the screen by a factor of two. Thus, the rectangle changed from $1.6^{\circ}$ wide $\times 1.1^{\circ}$ high to $3.2^{\circ}$ wide $\times 2.2^{\circ}$ high. The horizontal line changed only in length, over the same values as the width of the rectangle. The size of the stimulus on the monitor was varied so as to correspond to an object of a constant size moving toward and away from the observer at a constant simulated velocity of $25 \mathrm{~cm} / \mathrm{sec}$. Two rectangular posts, $8 \mathrm{~cm}$ high $\times 1.5 \mathrm{~cm}$ in cross section, were mounted in a horizontal track in front of the observer. The posts and track were hidden from view by black cloth, so that the adjusted separations of the posts were made by touch. The right post 
was fixed in position, and lateral adjustments were made in the position of the left post so that the felt space between their flat inner surfaces represented the perceptual characteristic being judged.

Procedure. The perceived distance of the stimulus was controlled on each trial by the position of the background in the alley, with the physical distance of the monitor in the adjacent alley always being constant. Because of the equidistance tendency, the stimulus, when not expanding or contracting (the static presentations), appeared to be just in front of the perceived location of the background. Three background positions, at 70,105 , and $140 \mathrm{~cm}$ from the observer's eyes, were used. Either the line or the rectangle could be presented with each of these background distances. On any trial, the observer was first asked to give a verbal estimate of the distance to the background and to the stimulus. The observer then used separation of the posts to indicate the horizontal perceived size of the stimulus prior to an expansion. The angular expansion, followed by contraction with no pause at either the near or the far simulated distances, was then started, and the observer was asked to adjust the separation of the posts to indicate the perceived horizontal size of the stimulus at its nearest and farthest apparent distances. In addition, the observer adjusted the separation of the posts to indicate the extent of the perceived motion in depth. Using the same posts that had been used for the size judgments, the observer indicated a sagittal perceived motion by adjusting the lateral separation of the inner surfaces of the posts. Although this measure was less direct than the sagittal separations of the posts used in the previous experiments, the observers did not report having any difficulty with the task. Each of the stimuli was seen three times against each of the three backgrounds. The order of presentation of the backgrounds was counterbalanced across subjects, and the sequence of stimuli presentation was random for each background.

\section{Results}

Table 7 shows the results of the experiment. For each background position, the values given are the mean judgments of the line and the rectangle stimuli. The perceived distances to the static stimuli at the far simulated distances and to the background are based on verbal reports. The perceived sizes (Dynamic $S_{f}^{\prime}$ and Dynamic $S_{n}^{\prime}$ ) and motions in depth ( $d^{\prime}$ from direct measures) are derived from the observer's adjustments of the lateral separation of the posts. First, it can be seen that the perceived distance to the background increased with its physical distance, although this physical distance was consistently underestimated by around $30 \%$. The perceived distance to the stimulus also increased with the perceived distance to the background, typically appearing to be some distance in front of it. Thus, the verbal reports corroborated the expectation that the equidistance tendency would increase the perceived distance of the stimulus, as the physical distance of the background was increased. The static perceived sizes of both the rectangle and the line increased with the perceived background distance, as would be expected from size-distance invariance. The results obtained from the two stimuli (line and rectangle) were very similar, and gave an indirect measure of perceived distance (using static reported size $S_{f}^{\prime}$ and Equation 1) of 77, 88, and $98 \mathrm{~cm}$ for the three background positions. When seen during optical expansion and contraction, the stimuli appeared to increase and decrease in size and to decrease and increase in distance, respectively. Analysis of variance showed that the perceptually far sizes were significantly different as a function of background distance $[F(2,10)=15.28, p<.01]$, but that there was no difference between the two kinds of stimuli and no interaction $[F(1,5)=1.9$ and $F(2,10)=1.4$, respectively $]$. By contrast, although the near sizes also varied significantly with background distance $[F(2,10)=31.0, p<.01]$, there was a significant difference between the line and the rectangle, such that the line appeared somewhat smaller $[F(1,5)=11.49, p<.05]$. There was no interaction between the two factors $[F(2,10)=0.53]$. For both the line and the rectangle, the ratios of near to far perceived dynamic sizes did not differ significantly from the 2:1 ratio of the visual angles subtended by the stimuli at these simulated distances. For the 70-, 105-, and 140-cm background distances, these ratios of perceived size were $1.85,1.90$, and 1.81 for the line and $2.05,1.83$, and 2.04 for the rectangle.

The perceived motions in depth also showed a significant variation with the three perceived distances of the background or of the stimulus $[F(2,10)=4.97, p<.05]$, and the extent of this motion was greater for the rectangle than for the line $[F(1,5)=15.16, p<.01]$. There was no interaction $[F(2,10)=0.12]$. The effect of background or stimulus distance on the perceived motion in depth from the optical expansion pattern was in the direction predicted from Equation 4. That is, the same angular change gave rise to a larger perceived motion in depth,

Table 7

Mean Perceived Characteristics (in Centimeters) of Background and Line or Rectangle in Experiment 4, for Three Physical Distances of the Background (70, 105, and $140 \mathrm{~cm})$

\begin{tabular}{|c|c|c|c|c|c|c|c|}
\hline \multicolumn{2}{|c|}{ Physical Characteristics } & \multicolumn{6}{|c|}{ Perceived Characteristics } \\
\hline $\begin{array}{l}\text { Physical } \\
\text { Background } \\
\text { Distance }\end{array}$ & $\begin{array}{l}\text { Kind of } \\
\text { Stimulus }\end{array}$ & $\begin{array}{l}\text { Background } \\
\text { Distance } D^{\prime}\end{array}$ & $\begin{array}{c}\text { Static } \\
\text { Stimulus } \\
\text { Distance } D_{f}^{\prime}\end{array}$ & $\begin{array}{c}\text { Static } \\
\text { Stimulus } \\
\text { Size } S_{f}^{\prime}\end{array}$ & $\begin{array}{c}\text { Dynamic } \\
\text { Stimulus } \\
\text { Size } S_{f}^{\prime}\end{array}$ & $\begin{array}{c}\text { Dynamic } \\
\text { Stimulus } \\
\text { Size } S_{n}^{\prime}\end{array}$ & $\begin{array}{c}d^{\prime} \text { from } \\
\text { Direct } \\
\text { Measures }\end{array}$ \\
\hline $70 \mathrm{~cm}$ & $\begin{array}{l}\text { rectangle } \\
\text { line }\end{array}$ & $\begin{array}{l}47.3 \\
47.7\end{array}$ & $\begin{array}{l}42.6 \\
41.8\end{array}$ & $\begin{array}{l}2.1 \\
2.2\end{array}$ & $\begin{array}{l}2.0 \\
2.0\end{array}$ & $\begin{array}{l}4.1 \\
3.7\end{array}$ & $\begin{array}{l}5.8 \\
4.0\end{array}$ \\
\hline $105 \mathrm{~cm}$ & $\begin{array}{l}\text { rectangle } \\
\text { line }\end{array}$ & $\begin{array}{l}65.1 \\
65.9\end{array}$ & $\begin{array}{l}54.5 \\
55.3\end{array}$ & $\begin{array}{l}2.4 \\
2.5\end{array}$ & $\begin{array}{l}2.4 \\
2.1\end{array}$ & $\begin{array}{l}4.4 \\
4.0\end{array}$ & $\begin{array}{l}5.9 \\
3.7\end{array}$ \\
\hline $140 \mathrm{~cm}$ & $\begin{array}{l}\text { rectangle } \\
\text { line }\end{array}$ & $\begin{array}{l}94.3 \\
94.4\end{array}$ & $\begin{array}{l}67.2 \\
74.4\end{array}$ & $\begin{array}{l}2.8 \\
2.7\end{array}$ & $\begin{array}{l}2.7 \\
2.7\end{array}$ & $\begin{array}{l}5.5 \\
4.9\end{array}$ & $\begin{array}{l}6.9 \\
4.7\end{array}$ \\
\hline
\end{tabular}

Note-Perceived background and stimulus distances were based on verbal reports; other values were obtained from post settings. 
for a greater initial perceived distance. It should be noted that the perceived motion in depth was relatively small, compared with that simulated. From Equation 4, for a $\theta_{f} / \theta_{n}$ of $1 / 2, d_{c}=D_{f}^{\prime} / 2$. The stimulus at its largest size should have been perceived at an egocentric distance that was one-half of the distance perceived at its smallest size. Clearly, the apparent motion in depth was only a fraction of this. It is likely that the equidistance tendency not only altered the perceived distance of a stimulus, but also restricted its apparent motion in depth.

\section{Discussion}

The changes in reported motion in depth in this experiment, although small, suggest, in agreement with Equation 4, that the magnitude of the perceived motion in depth, due to the secondary process, varies directly with the magnitude of the perceived distance of the stimulus at its smallest angular size $\left(S_{f}^{\prime}\right)$.

Experiment 4 is particularly important in testing Equation 4 because an aspect of the results from Experiment 1 might otherwise be interpreted as supporting a different conclusion. It will be noted in Table 1 that the column labeled "Predicted Depth Motion," using Equation 4, indicates that the predicted values of depth motion tend to be smaller for the larger "far" starting sizes of the stimulus line. Thus, the average reported depth (from Equation 4) predicted for the $3.0-\mathrm{cm}$ line is $19.8 \mathrm{~cm}$, for the $5.0-\mathrm{cm}$ line is $18.3 \mathrm{~cm}$, and for the $7.0-\mathrm{cm}$ line is $17.0 \mathrm{~cm}$. The reason for these different predictions is that, according to the $S_{f}^{\prime}$ results, the $3.0-\mathrm{cm}$ line was perceived at $63.5 \mathrm{~cm}$, the $5.0-\mathrm{cm}$ line at $59.1 \mathrm{~cm}$, and the $7.0-\mathrm{cm}$ line at $55.5 \mathrm{~cm}$. However, the average perceived depth found by direct measures does not follow these predictions. As calculated from the "Direct Measurement" data of Table 1, the average $d^{\prime}$ for the $3.0-\mathrm{cm}$ line is $9.0 \mathrm{~cm}$, for the $5.0-\mathrm{cm}$ line is $10.0 \mathrm{~cm}$, and for the $7.0-\mathrm{cm}$ line is $11.1 \mathrm{~cm}$. It seems that the factor of starting line length in addition to perceived distance and the change of visual angles can modify the measured apparent motion in depth.

\section{GENERAL DISCUSSION AND CONCLUSIONS}

The experiments described here have immediate consequences for two related phenomena: (1) the sizedistance invariance hypothesis, and (2) the perceptions associated with the optical expansion pattern.

\section{Validity and Limitations of the SDIH}

Consider the results from the present research in which the only source of information available to indicate object motion toward or away from the observer was the optical expansion pattern (Experiments 1, 3, and 4 and Condition 2 of Experiment 2). In these cases, the results cannot be reconciled with the requirement of the SDIH that substantial apparent motions in depth, in the direction expected from the optical expansion pattern, will occur only if the ratio of perceived sizes of the stimulus is substantially less than the ratio of retinal sizes. More formally, from the present results, perceived motion in depth from the optical expansion pattern is inconsistent with the statement (Equation 2 of the SDIH) that $d^{\prime}=S_{f}^{\prime} / \tan \theta_{f}$ $-S_{n}^{\prime} / \tan \theta_{n}$. Nor can this limitation be dismissed by supposing that the reported sagittal motion from optical expansion is not a perception of motion in depth. Using the head-motion procedure as a criterion measure, it was found, to some extent in Experiment 2 and unequivocally in Experiment 3, that the indicated motion in depth was, indeed, perceptual. This restriction on the SDIH, however, does not mean that the SDIH will not apply when the perception of object motion is supported by sources of information other than or in addition to optical expansion. On the contrary, in Condition 1, Experiment 2 , in which the visual angle was constant and convergence was varied, $S^{\prime} / \tan \theta$ increased as convergence increased. Similarly, in Condition 3, Experiment 2, both convergence and optical expansion varied in the same direction, and a large apparent motion in depth was present in the direction expected from Equation 2 of the SDIH. Indeed, even in instances in which the response of sagittal motion cannot be explained by the SDIH, primary processes of $S^{\prime}$ and $D^{\prime}$ are necessary to activate the secondary processes responsible for the distance response, with this interrelation of primary and secondary processes expressed by Equations 3, 4, and 5 .

Thus, the present study reveals a limitation of the SDIH in that the SDIH is insufficient to explain the relation between perceived size and distance obtained from optical expansion. But this study also asserts the importance of the SDIH. The direction of the relationship between $S^{\prime}$ and $D^{\prime}$ agrees with the SDIH when distance information other than optical expansion is available, and the primary process, specified by the SDIH, provides information essential for the apparent sagittal motion from optical expansion.

\section{Validity and Limitations of Optical Expansion as a Source of Spatial Information}

The apparent motion in depth associated with the optical expansion pattern can be consistent with the SDIH, as shown by the results from Condition 3 of Experiment 2 , in which convergence changes and optical expansion were in agreement. This is indicated by comparing the measures of $d^{\prime}$, obtained directly from the post adjustment $(11.5 \mathrm{~cm})$, with the predicted $d^{\prime}$ from Equation 2 using the Dynamic $S^{\prime}$ data $(11.0 \mathrm{~cm})$, as listed in Table 4 . But, in the absence of the cue of convergence in Experiments 1 and 3, the predicted values of $d^{\prime}$ from Equation 2, using Dynamic $S^{\prime}$ data, were in the direction opposite to the results obtained from the sagittal adjustments of the posts. The report of motion in depth under conditions in which none is expected from the SDIH because of the equality of ratios of perceived and optical sizes is explained by the interrelation of primary and secondary processes. The primary process results in $S^{\prime}$ and $D^{\prime}$ and is reflected in the SDIH. The secondary process results 
in $S_{c}$ and $D_{c}$, with Equation 3 specifying the interrelation between the two processes. As has been discussed, these two processes and their interrelation have been identified in previous research. What is new in the present study is their application to the responses associated with the optical expansion pattern and the finding that the secondary process can have a robust effect on perceived distance. This is indicated particularly by the results from the head-motion procedure in Experiment 3. Previously, only a rather weak effect from the secondary process on perceived distance was found and only with the familiar size cue of distance (Gogel, 1976). However, the present study also provides some evidence that the response of motion in depth from optical expansion need not always be perceptual. In Condition 4, Experiment 2, the opposition of convergence changes and optical expansion resulted in the canceling of apparent motion in depth as measured by the head-motion procedure but not by the post adjustments. It seems likely that as more cues in opposition to the perceived depth from optical expansion are added, either as a constant constraint as in Condition 2, Experiment 2 or as an opposing change as in Condition 4, Experiment 2, the response of motion in depth from optical expansion will shift from the perceptual to the cognitive domain. Common instances of a response to motion in depth from optical expansion, probably consistent with the two-process explanation and probably inconsistent with the SDIH, are found in the simulation of depth motion on the television or cinema screen. Expanding or contracting images on the screen often appear to change markedly in distance while simultaneously exhibiting substantial changes in perceived size. Research is required, however, before it can be decided whether this simultaneous perception of changing distance and changing size is, indeed, inconsistent with the SDIH, as expressed in Equation 2.

\section{Alternative Explanations and Related Research}

An explanation of the phenomena examined in this study alternative to that of the interrelation of two processes can be rejected by the data. This alternative explanation is that the observers perceived a motion in depth and a constant object size in agreement with the SDIH, but the report of size rather than reflecting perceived size was dominated by a direct response to angular size unmodified by perceived distance. Such an explanation is at variance with any results indicating that the reported size in these experiments was modified by perceived distance. Results of this kind are found in the effect of the specific distance tendency (Experiments 1 and 2) and the equidistance tendency (Experiment 4) on both perceived size and perceived distance. Also, in the instances in which a change in convergence was an effective modifier of the apparent distance of the line stimulus (Conditions 1 and 3, Experiment 2), the perceived size of the line was modified systematically by its perceived distance, as expected from the SDIH. In addition, if a direct response to angular size had been made, this should have been a function of the sagittal distance of the horizontally separable posts from the observer. Since this distance always was $30 \mathrm{~cm}$ and the screen distance was $45 \mathrm{~cm}$, observers' settings would have been approximately $66 \%$ of the angular size of the stimulus at the eye. Such a relationship is not present in the data from any of the experiments.

A second alternative explanation of the failure of the data to conform to the SDIH in the case of optical expansion is that the tactile procedure for measuring perceived size introduced a systematic error into the data. Suppose this error was such that the tactile measure increased more rapidly as a function of visual angle than was warranted by the increase in perceived size. Thus, a small increase in perceived size as the angle expanded would be measured incorrectly as a large increase in perceived size, for example, as an increase in perceived size equal to the increase in visual angle. If this were the case, the change in perceived size, had it been measured correctly, might have been consistent with the change in perceived motion in depth, as specified by the SDIH. The validity of the tactile method of measuring perceived size was tested in a small supplementary experiment using 4 observers who had taken part in Experiment 4. The rationale of the test was that in the case in which many cues of distance are available, the perception of size should be veridical and, therefore, that any errors in measuring the perceived size of the test stimulus by the tactile method could be attributed to inaccuracies in the tactile measure. For this purpose, the line and rectangular stimuli of Experiment 4 were viewed binocularly rather than monocularly, with the monitor physically placed in the illuminated alley at a distance of $110 \mathrm{~cm}$. Each stimulus from Experiment 4 was presented both statically and with the same expansion and contraction as in Experiment 4. The apparent motion in depth was very small or absent due to the strength of cues to the distance of the monitor and the zero binocular disparity with respect to the monitor and test stimuli, so that the observers reported seeing little or no motion in depth. Three adjustments of the lateral separation of the posts, as used in Experiment 4, were made by each observer to indicate the apparent width of each stimulus. The mean perceived sizes of the static line and rectangle were 3.0 and $3.1 \mathrm{~cm}$, respectively, which corresponds very closely to the physical size of $3 \mathrm{~cm}$. During the expansion and contraction, the tactile size adjustments indicating the perceived sizes of the large and small stimuli were 2.9 and $6.0 \mathrm{~cm}$ for the line and 3.0 and $6.0 \mathrm{~cm}$ for the rectangle. Again, these were very close to the physical sizes of the stimuli. Additional support for the validity of the tactile method of measuring perceived size is found in a previous study (see Gogel, Loomis, Newman, \& Sharkey, 1985, Footnote 3). It seems, therefore, that the data of this study, including the tendency for the ratios of the perceived sizes to exceed those of the retinal sizes, cannot be attributed to measurement errors from the tactile procedure. The latter result contrasts with Swanston and Wade's (1984) report that continuous change in the width of a vertical line produced by video 
zooming tends to be underestimated. However, in that study, there was a clearly visible surround to the illuminated field on which the line appeared and concurrent measures of motion in depth were not obtained. The difference in conditions was therefore such as to prevent any straightforward comparison with the present results.

The presence of two processes, primary and secondary, in the perception of size and distance has also been postulated by other researchers. Gillam's (1980) theory of geometrical illusions and the research generated by this theory suggest that linear perspective and foreshortening cues of distance can modify perceived size (the primary process) without simultaneously modifying perceived distance (the secondary process). It is concluded from Gillam's research that the geometrical stimuli, physically and perceptually at a constant distance from the observer, tend to have perceived sizes as if they were distributed in depth. Like the results of the present study, this involves a dissociation of perceived size and perceived distance in opposition to the SDIH, but, unlike the present study, it was the perceived size, not the perceived depth, that differed from the distal conditions. An explanation of the interrelation of size and distance responses in terms of primary and secondary processes has been described by Higashiyama $(1977,1979,1983)$. This explanation has some similarities with (and differences from) the theory (Gogel, 1971, 1974, 1976) described and applied in the present study. In his 1977 article, Higashiyama discusses and applies his theory to the situation (similar to that of the present study) in which objects of the same shape but differing in visual angle are presented at a constant distance. In this case, a pure primary process, supported by oculomotor cues of distance, is expected to result in the differently sized objects' being perceived as having sizes proportional to their visual angles. Opposed to this primary process is a secondary process which, in its pure form, would result in the objects' being perceived as constant in size and inversely related in distance with respect to their retinal sizes. To explain the results obtained in the present study, the perceived sizes of the stimuli would need to be determined entirely by the primary process with the perceived distances determined by the secondary process. From the theory of Higashiyama, however, it does not seem that this could happen, since in that theory the secondary perceptions of different distances requires the occurrence of the secondary perceptions of equal sizes.

The optical expansion pattern often is regarded as a source of effective information regarding motion in depth (Gibson, 1958, 1979; Gibson, Olum, \& Rosenblatt, 1955). But the optical expansion pattern as a cue of distance has some limitations. The perception of motion in depth, using optical expansion, cannot be considered to be exclusively a function of information provided by the expanding or contracting pattern. As indicated by Equation 4 and supported by Experiment 4, the apparent magnitude of the motion in depth is related to the perception of the starting distance of the stimulus. The motion is expected to appear smaller (and slower) if the starting dis- tance is underperceived and larger (and faster) if it is overperceived. The veridical perception of motion in depth, therefore, requires additional information, independent of the change in image size.

The response to optical expansion (looming) has been used as an index of the development of the perception of distance. A defensive response to looming has been measured in a variety of animals (Schiff, 1965), and the evidence favors its occurrence in infants at about 3 months of age (Yonas \& Granrud, 1985). Clearly, this sensitivity to optical expansion in both infants and animals places severe limits on the cognitive processes that can be postulated in any general explanation of responses to visual phenomena, including optical expansion. According to the present study, $S_{c}$ in $S_{c} / S^{\prime}$ involves a short-term memory process. If $D_{c}$ is perceptual, as was shown in Experiment 2 and more clearly in Experiment 3, then $S_{c}$ is the only representational (memory) component involved in the response. It should be noted that such memorial processes are basic to a variety of perceptual phenomena. They are required, for example, in the kinetic depth effect, in anorthoscopic perception (whether produced by "postretinal storage" or "retinal painting"), in the integration of successive glances, and probably in the perception of the path of a moving object. But, even in the case in which $D_{c}$ is "cognitive" and not "perceptual," the representational requirements are not severe. Indeed, it seems likely that they are no more severe than the ability to use familiar size as a cue to distance, which, according to Yonas, Pettersen, and Granrud (1982) and Granrud, Haake, and Yonas (1985), occurs at about 7 months of age.

\section{REFERENCES}

Carlson, V. R. (1960). Overestimation in size constancy judgments. American Journal of Psychology, 73, 199-213.

Carlson, V. R., \& TASSONE, E. P. (1962). A verbal measure of perceptual attitude. American Journal of Psychology, 75, 644-647

EмmeRT, E. (1881). Grossenverhältnisse der Nachbilder. Klinische Monatsblatt für Augenheilkunde, 19, 443-450.

GiBSON, J. J. (1958). Visually controlled locomotion and visual orientation in animals. British Journal of Psychology, 49, 182-194.

GiBson, J. J. (1979). The ecological approach to visual perception. Boston: Houghton Mifflin.

Gibson, J. J., Olum, P., \& Rosenblatt, F. (1955). Parallax and perspective during aircraft landings. American Journal of Psychology, 68, 372-385.

GiLINSKY, A. S. (1951). Perceived size and distance in visual space. Psychological Review, 58, 460-480.

Gillam, B. (1980, January). Geometrical illusions. Scientific American, 242, 101-111.

GoGEL, W. C. (1965). The equidistance tendency and its consequences. Psychological Bulletin, 70, 289-293.

GoGeL, W. C. (1969). The sensing of retinal size. Vision Research, 9, 1079-1094.

GoGEL, W. C. (1971). The validity of the size-distance invariance hypothesis with cue reduction. Perception \& Psychophysics, 9, 92-94.

Gogel, W. C. (1974). Cognitive factors in spatial response. Psychologia, 17, 213-225.

GoGEL, W. C. (1976). An indirect method of measuring perceived distance from familiar size. Perception \& Psychophysics, 20, 419-429.

GOGEL, W. C. (1981). The role of suggested size in distance responses. Perception \& Psychophysics, 30, 149-155. 
GOGEL, W. C. (1982). Analysis of the perception of motion concomitant with a lateral motion of the head. Perception \& Psychophysics, 32, 241-250.

GoGEL, W. C. (1984). The role of perceptual interrelations in figural synthesis. In P. C. Dodwell \& T. Caelli (Eds.), Figural synthesis (pp. 31-82). Hillsdale, NJ: Erlbaum.

Gogel, W. C., Loomis, J. M., Newman, N. J., \& Sharkey, T. J. (1985). Agreement between indirect measures of perceived distance. Perception \& Psychophysics, 37, 17-27.

Gogel, W. C., \& STURM, R. D. (1971). Directional separation and the size cue to distance. Psychologische Forschung, 35, 57-80.

Goget, W. C., \& TIETZ, J. D. (1973). Absolute motion parallax and the specific distance tendency. Perception \& Psychophysics, 13, 284-292.

Granrud, C. E., HaAke, R. J., \& Yonas, A. (1985). Infants' sensitivity to familiar size: The effect of memory on spatial perception. Perception \& Psychophysics, 37, 459-466.

Higashiy ama, A. (1977). Perceived size and distance as a perceptual conflict between two processing modes. Perception \& Psychophysics, 22, 206-211.

Higashiyama, A. (1979). The perception of size and distance under monocular observation. Perception \& Psychophysics, 26, 230-234.

HigashiYama, A. (1983). A variety of size and distance judgments under monocular observation: Instructions and individual differences. Human Science (The University of Osaka Prefecture, The Human Sciences Society), 13-14, 91-111.

IRWIN, R. J. (1969). Emmert's law as a consequence of size constancy. Perceptual \& Motor Skills, 28, 69-70.

ItTELSON, W. H. (1951). Size as a cue to distance: Radial motion. American Journal of Psychology, 64, 188-202.

Johansson, G. (1964). Perception of motion and changing form. Scandinavian Journal of Psychology, 5, 181-208.

KilPatrick, F. P., \& ItTelson, W. H. (1953). The size-distance invariance hypothesis. Psychological Review, 60, 223-231.

KING, W. L., \& Gruber, H. E. (1962). Moon illusion and Emmert's law. Science, 135, 1125-1126.

LEE, D. N. (1980). The optic flow field: The foundation of vision. Philosophical Transactions of the Royal Society(B), 290, 169-179.

MacCracken, P. J., Gogel, W. C., \& Blum, G. S. (1980). Effects of posthypnotic suggestion on perceived egocentric distance. Perception, 9, 561-568.

MaRmolin, H. (1973a). Visually perceived motion in depth resulting from proximal changes. I. Perception \& Psychophysics, 14, 133-142.

Marmolin, H. (1973b). Visually perceived motion in depth resulting from proximal changes. II. Perception \& Psychophysics, 14, 143-148.

NaKayama, K., \& Loomis, J. M. (1974). Optical velocity patterns, velocity-sensitive neurons, and space perception: A hypothesis. Perception, 3, 63-80.

NoGUCHI, K., \& TAYA, K. (1981). A neglected problem: Kinetic size constancy. Acta Psychologica, 48, 187-194.

Price, G. R. (1961). An Emmert's law of apparent sizes. Psychological Record, 11, 145-151.

REgAN, D., BEVERLEY, K. I. (1978). Looming detectors in the human visual pathway. Vision Research, 18, 415-421.

SCHIFF, W. (1965). The perception of impending collision: A study of visually directed avoidant behavior. Psychological Monographs, 79(11, Whole No. 604).

SCHLOSBERG, H. (1950). A note on depth perception, size constancy, and related topics. Psychological Review, 57, 314-317.

Swanston, M. T., \& WADE, N. J. (1984). Illusions of size change in dynamic displays. Perception \& Psychophysics, 35, 286-290.
Weintraub, D. J., \& Gardner, G. T. (1970). Emmert's laws: Size constancy versus optical geometry. American Journal of Psychology, 83, 40-54.

WheAtstone, C. (1852). Contributions to the physiology of visionPart the second. On some remarkable, and hitherto unobserved, phenomena of binocular vision. Philosophical Transactions of the Royal Society, 142, 1-17.

Yonas, A., \& Granrud, C. E. (1985). Development of visual space perception in young infants. In J. Mehler \& R. Fox (Eds.), Neonate cognition: Beyond the blooming buzzing confusion. Hillsdale, $\mathrm{NJ}$ : Erlbaum.

Yonas, A., Pettersen, L., \& Granrud, C. E. (1982). Infants' sensitivity to familiar size as information for distance. Child Development, 53, $1285-1290$.

\section{APPENDIX}

A Glossary of Terms

\begin{tabular}{|c|c|}
\hline Term & Definition \\
\hline$S$ & Physical size of the stimulus \\
\hline$D$ & Physical distance of the stimulus from the observer \\
\hline$\theta$ & Visual angle of the stimulus \\
\hline$S^{\prime}$ & Perceived size of the stimulus \\
\hline$D^{\prime}$ & $\begin{array}{l}\text { Primary perceived distance of the stimulus from the ob- } \\
\text { server }\end{array}$ \\
\hline$d^{\prime}$ & $\begin{array}{l}\text { Perceived depth between the farthest and nearest simu- } \\
\text { lated distances from the observer }\end{array}$ \\
\hline$S_{c}$ & $\begin{array}{l}\text { Observer's remembered size of the stimulus as perceived } \\
\text { at the start of the optical changes in size }\end{array}$ \\
\hline$D_{\text {c }}$ & $\begin{array}{l}\text { Perceived or cognitive distance as influenced by remem- } \\
\text { bered size }\end{array}$ \\
\hline$d_{c}$ & $\begin{array}{l}\text { Perceived or cognitive depth between the near and far } \\
\text { simulated distances as influenced by remembered size }\end{array}$ \\
\hline$K$ & $\begin{array}{l}\text { Lateral extent of the physical motion of the observer's } \\
\text { head }\end{array}$ \\
\hline$W^{\prime}$ & $\begin{array}{l}\text { Perceived lateral motion of the stimulus concomitant with } \\
\text { the lateral motion of the head }\end{array}$ \\
\hline Static $S^{\prime}$ & $\begin{array}{l}\text { Perceived size of the stimulus prior to viewing of the op- } \\
\text { tical changes in size }\end{array}$ \\
\hline & Perceived size of the stimulus at a terminal simulated dis- \\
\hline
\end{tabular}

Dynamic $S^{\prime}$ Perceived size of the stimulus at a terminal simulated distance following viewing of the optical changes in size

Static $W^{\prime} \quad$ Perceived lateral motion of the stimulus concomitant with the lateral motion of the head prior to viewing of the optical changes in size

Dynamic $W^{\prime}$ Perceived lateral motion of the stimulus concomitant with the lateral motion of the head at a terminal simulated distance following viewing of the optical changes in size

Note: Subscripts $n$ and $f$, when used in the text or figures, with $S, S^{\prime}$, $D, D^{\prime}, W^{\prime}$, and $\theta$, indicate the particular physical or perceived characteristic of the stimulus of the nearest and farthest distances from the observer as simulated by the optical changes (expansion or contraction) in size.

(Manuscript received December 6, 1985; revision accepted for publication April 11, 1986.) 